\title{
Macroeconomic Effects of Job Reallocations: A Survey
}

\author{
GIOVANNI GALLIPOLI \\ University of British Columbia, Canada; Becker-Friedman Institute, University of \\ Chicago, USA; and Rimini Centre for Economic Analysis, Italy ${ }^{1}$
}

\section{GIANLUIGI PELLONI}

Wilfrid Laurier University, Canada; The Johns Hopkins University, SAISBologna, Italy; and Rimini Centre for Economic Analysis, Italy.

\begin{abstract}
This paper appraises the literature on the macroeconomic effects of job reallocations. We overview different methodological approaches to the problem of observational equivalence of aggregate and sectoral shocks and draw two main conclusions. First, the non-directional nature of reallocation shocks holds the key to the fundamental identification problem. The second conclusion is that sectoral reallocation of labor has been responsible for no less that $1 / 4$ and no more that $2 / 3$ of the variance of aggregate unemployment in postwar data. This wide range indicates that the importance of labor reallocation may change over time, being larger at particular historical junctures.
\end{abstract}

Keywords: Labor Reallocation, Unemployment, Sectoral Shifts, Methodology, Assessment

JEL Classification Numbers: E30, C10 , J2

\section{Introduction}

We discuss this problem of observational equivalence in detail and appraise critically the methods that have characterized the empirical literature on sectoral shifts from publication of Lilien's seminal work to present. As a guiding principle for our excursion we track the

\footnotetext{
${ }^{1 *}$ We wish to thank Karim Abadir, John Addison, Dwayne Benjamin, Ramazan Gencay, Angelo Melino, Theodore Panagiotidis and many conference and seminar participants for useful comments over the years. Guidon Fenig provided excellent research assistance as well as extensive comments on several drafts of this paper.

Correspondence: Vancouver School of Economics, UBC, 997-1873 East Mall, Vancouver, BC, V6T1Z1, Canada. Tel: +1 (604) 7821717. E-mail: gallipol@mail.ubc.ca.

(C) 2013 Giovanni Gallipoli and Gianluigi Pelloni. Licensed under the Creative Commons Attribution Noncommercial 3.0 Licence (http://creativecommons.org/licenses/by-nc/3.0/. Available at http: //rofea.org.
} 
methodological development of the solutions to the aforementioned problem of observational equivalence. Part of the problem in identifying the effects of sectoral shifts stems from a difficulty that we wish to clarify from the outset: the notion of an aggregate shock is still vague and devoid of a clear and unambiguous meaning within a general equilibrium context (Black, 1995, often refers to this issue). Our view is that aggregate shocks can only be defined vis-a-vis reallocation shocks. The latter are disturbances to the current allocation of resources which can bring about temporary spikes in unemployment due to workers' flows. In contrast, aggregate impulses must have a specific sign and directional implications for the activity of all sectors/firms, meaning that they induce either an expansion or a reduction in employment in all sectors. This view, though not an operational definition yet, suggests specific empirical features on which to build a meaningful identification argument. If one had to come up with an operational definition, then Davis (1987) suggests that aggregate shocks should be seen as the cross-sectional average of marginal product disturbances. Throughout this article we consider Davis's definition as the most accurate approximation to the concept of aggregate shock.

Our work is organized as follows: in Section 2 we outline the SSH in its original formulation and provide a description of the empirical approach which characterized the seminal contributions. This section ends by reviewing the observational equivalence controversy surrounding different tests of the hypothesis and by classifying alternative approaches. Section 3.1 discusses the so-called 'purging' methodology and outlines two testable implications of the SSH and the evidence supporting each of them. Section 3.2 surveys the effectiveness of the unemployment-vacancy relationship as a discriminating tool. Section 3.3 describes alternative measures of sectoral shocks based on stock market prices. Section 3.4 introduces an upgrade in modeling sectoral shocks via vector auto-regressions, VAR, which is free of generated dispersion indexes. In Section 4 and its subsections the job creation and job destruction approach, initiated by Davis and Haltiwanger (1990; 1992), is discussed. We emphasize the potential of this contribution as a 'discriminating' testing tool. Section 5 is entirely devoted to models which rely on micro-level data. Finally, another increasingly popular way to explore the SSH is via numerical simulation techniques based on well specified equilibrium models: this approach is the subject of section 6 . Section 7 provides a summary of the paper, draws broad conclusions and presents possible directions for future research.

A word of warning: throughout this article we use acronyms to identify some often cited authors, papers and definitions. We always define an acronym before using it and for reference we report the list of all acronyms at the end of the paper. 


\section{GALLIPOLI, PELLONI Macroeconomic effects of Job Reallocations: A Survey}

\section{Lilien's Sectoral Shifts Hypothesis}

The SSH provides a prototype structure for a class of models dealing with the aggregate effects of reallocation shocks. The fundamental intuition behind the SSH has ancient roots, with classical economists from the 19th century, such as Ricardo (1817, ch.19), well aware of this possibility. Despite such early recognition, modern economics did not explore the potential effects of reallocation shocks on aggregate economic activity until the early 1980s, see Sheffrin (1997). In this sense, David Lilien's contribution was path-breaking.

Lilien's dispersion hypothesis claims that inter-sectoral shifts in demand composition are a driving force of unemployment fluctuations. The basic insight is that idiosyncratic shocks bring about flows of employment reallocation from declining sectors to expanding ones. Such labor reallocation may be slow and entail prolonged unemployment spells. Therefore, the higher the dispersion of employment demand throughout the economy the higher aggregate unemployment will be. Lilien resorts to a model by Lucas and Prescott (1974) (LP) for the theoretical underpinnings of his hypothesis. LP develop a intersectoral reallocation model of the natural rate of unemployment within a Phelpsian islands economy (Phelps, 1970) characterized by spatially separated competitive markets. Local random demand shocks bring about temporary wage differentials across markets which in turn lead to labor reallocation from low wage sectors to high wage sectors. As the adaptive capability of the economy is limited the required adjustments to local shocks are not instantaneous, and thus a positive unemployment rate will exist in equilibrium. In LP's setting this natural rate of unemployment (NRU) is constant because the stochastic process governing demand composition is covariance stationary and idiosyncratic shocks average out across sectors. Lilien crucially removes the assumption of stationarity and extends the LP model to allow for a fluctuating NRU. This results in a turnover model of the labor market in which a pivotal role is played by the stochastic net hiring equation,

$$
y_{i t}=Y_{t}+\varepsilon_{i t}
$$

The typical firm's net hiring $y_{i t}$ is decomposed in an aggregate hiring rate $Y_{t}$ common to all firms and a firm specific component $\varepsilon_{i t}$. The properties of the stochastic process $\left\{\varepsilon_{i}\right\}_{t}$ characterize the $\mathrm{SSH}$. The random variable $\varepsilon_{i t}$ is distributed as $\varepsilon_{i t} \sim\left(0, \sigma_{i t}^{2}\right)$, with the timeperiod subscript $t$ attached to $\sigma_{i}^{2}$ indicating the time dependence of the variance. The time changing variance, $\sigma_{i t}^{2}$, drives fluctuations in aggregate unemployment and in the NRU. In Lilien's view fluctuations of aggregate unemployment are not necessarily deviations from a stable NRU due to aggregate (i.e., non sector-specific) disturbances. By imposing restrictions on the firm's hiring-layoff behavior and appealing to the Law of Large Numbers an aggregate layoff function can also be derived: 


$$
L_{t}=g\left(Y_{t}, \sigma_{t}\right)
$$

where $\sigma_{t}$ denotes a measure of overall hiring dispersion which is positively related to layoffs. Higher hiring dispersion leads to a larger aggregate volume of layoffs. Inserting this equation within a simple flow model allows Lilien to derive a dynamic reduced form equation for the unemployment rate which can be generalized as:

$$
u_{t}=F\left\{A(L) u_{t}, B(L) \sigma_{t}, C(L) z_{t}\right\}
$$

where $A(L), B(L)$ and $C(L)$ are polynomials in the lag operator $L, u_{t}$ and $\sigma_{t}$ are measures of unemployment rate and of inter-sectoral dispersion of demand conditions and $z_{t}$ is a vector of aggregate control variables. Equation (3) suggests that, after controlling for serial correlation and aggregate factors, unemployment could still be sensitive to sectoral shifts.

Lilien approximates the variance of reallocation shocks using the standard deviation of cross-sectoral employment growth rates from an eleven-sectors decomposition of the US economy,

$$
s_{t}=\left[\sum_{i=1}^{K} w_{i t} \cdot\left(\Delta \ln x_{i t}-\Delta \ln x_{t}\right)^{2}\right]^{\frac{1}{2}}
$$

where $x_{i t}$ is employment in sector $i$ at time $t, x_{t}$ is aggregate employment at time $t, K$ is the number of sectors and $w_{i t}$ are weights defined as the relative size of each sector, that is $\left(\frac{x_{i t}}{x_{t}}\right)$. Using US annual data from 1948 to 1980, Lilien estimates a linearized version of equation (3) including the dispersion proxy $s_{t}$ :

$$
u_{t}=\alpha_{0}+\alpha_{1} s_{t}+\sum_{\forall j} \alpha_{j} z_{t-j}+e_{t}
$$

His results bear out that $s_{t}$ is significantly and positively correlated with unemployment over the sample period. The evidence suggests that much of US unemployment in the 1970's, contrary to that of the early 1960's, can be explained by sectoral shifts. Demand management policies were then ill suited for that specific unemployment spate; instead speeding up the process of labor reallocation would have had a stronger impact on unemployment.

\subsection{Auxiliary Implications of the Sectoral Shifts Hypothesis}

The SSH mechanism has auxiliary implications which in principle might be tested. Two such testable restrictions of the $\mathrm{SSH}$, which can be easily incorporated in estimable models with a dispersion proxy, are originally set forth by Davis (1987). We refer to them as, respectively, (1) the 'Past-Patterns-of-Labor-Reallocation' (PPLR) effect on current employment and, (2) 


\section{GALLIPOLI, PELLONI Macroeconomic effects of Job Reallocations: A Survey}

the 'Stage-of-Business-Cycle-Effect' (SBCE) in the relationship between unemployment and the dispersion proxy.

Past Patterns of Labor Reallocation. The PPLR is an important source of information because of workers' attachment to specific sectors. Such attachment results from barriers to labor mobility due to sector-specific human capital, lump-sum sector-switching costs and other obstacles (e.g. sectoral/wage differentials reflecting non competitive forces). These obstacles make the contemporaneous response of aggregate unemployment to inter-sectoral reallocations depend on past patterns of labor reallocation. This is how it works: consider any sectoral shock which intensifies an already existing mismatch of skills, location and information; such a shock would reinforce past patterns of labor reallocation and substantially increase unemployment. In contrast, a reallocation shock reversing recent past patterns of job reallocations would be accompanied by little or no increase, or possibly a decrease, in unemployment; the rationale for this last statement is that workers who have recently switched industries would find it easier to return to the original sectors because of sector specific human capital, personal contacts and information. These alternative implications of the SSH are testable and Davis (1987) suggests computing the following 'horizon covariances' as measures of the current direction of inter-sectoral reallocations relative to past directions:

$$
s_{t, j}^{H}=\sum_{i=1}^{K} w_{i t}\left(\Delta_{1} \ln x_{i t}-\Delta_{1} \ln x_{t}\right)\left(\Delta_{j} \ln x_{i, t-1}-\Delta_{j} \ln x_{t-1}\right) \text { with } j=1,2, \ldots, J
$$

Here $x_{i t}$ is employment in sector $i$ at time $t$, and the $s_{t, j}^{H}$ are weighted cross-sectoral covariances between the one-period inter-sectoral movements recorded at time $t$ and the $j$ period inter-sectoral movements recorded at time $(t-1)$. If the measured values of $s_{t, j}^{H}$ are relatively high, then the time $t$ direction of sectoral reallocations reinforces past labor reallocation patterns. Instead, lower values of the $s_{t, j}^{H}$ signal the reversing of past patterns. The SSH predicts that the index $s_{t, j}^{H}$ should enter a Lilien-type unemployment equation with a positive sign and Davis (1987) does find that horizon covariances display a positive sign and are statistically significant with both quarterly and annual US data over the period 1953-1986. Corroborating evidence based on UK data is offered by Mills, Pelloni, and Zervoyanni (1996, MPZ) who find evidence of PPLR effects using UK quarterly data for the period 1976-1991.

Stage of Business Cycle Effect. The SBCE derives from the observation that inter-sectoral reallocations imply foregone production. If the opportunity cost of unemployment is procyclical, rational agents have an incentive to shorten unemployment spells during expansions and lengthen them during recessions. Thus, for a given amount of labor reallocation, there should be less measured unemployment during expansions and more during recessions. Davis (1987) and Mills, Pelloni, and Zervoyanni (1995; 1996) perform tests of the SBCE by 
introducing recession interaction variables and their lags into unemployment equations. Davis rejects the SBCE. However the MPZ papers find evidence of significant SBCE on the relationship between the magnitude of labor mobility and unemployment. These differences are largely attributable to the updated econometric methodology in MPZ and provide additional supporting evidence to the SSH. Taken together, the evidence on PPLR and SBCE is far from conclusive but it does provide some supporting evidence for the empirical relevance of the SSH.

\subsection{Early Criticism of Lilien's Approach}

The SSH triggered a quick response from the economic profession. Simple inspection of Figure 1, where we plot Lilien's dispersion index (based on an eleven-sector decomposition of BLS data) and the US unemployment rate, would clearly suggest that there have been frequent strong comovements between unemployment and that sectoral shocks' proxy over both the sample period explored by Lilien and other episodes.

Figure 1: Dispersion index and Unemployment Rate

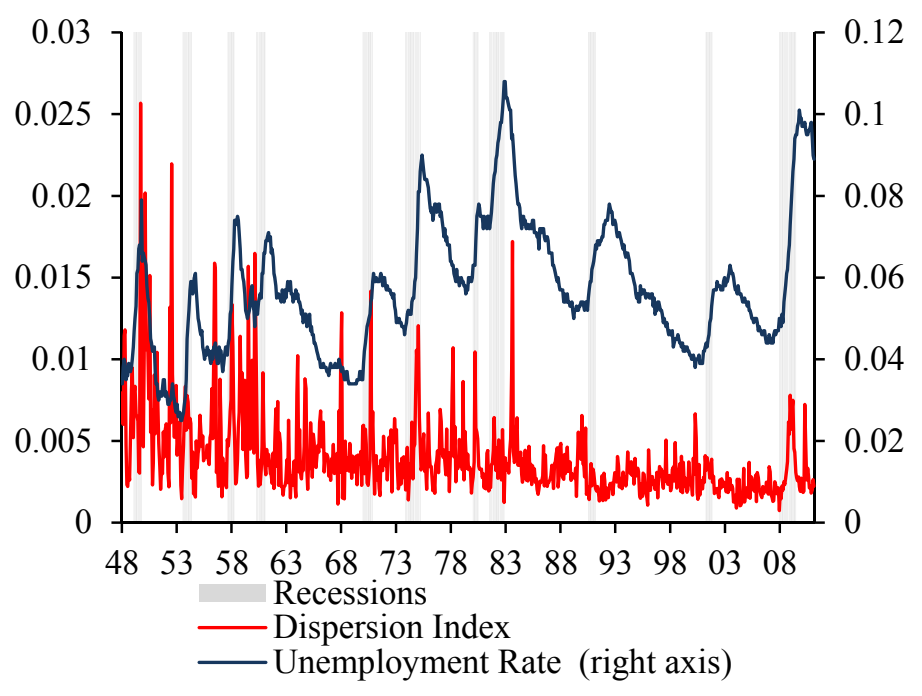

It was immediately recognized that a problem of observational equivalence was embedded in Lilien's approach, as discussed in Abraham and Katz (1984; 1986), Weiss (1986) as well as in Lilien (1982a). In fact, Lilien's dispersion proxy may reflect aggregate disturbances if cyclical responsiveness varies across sectors. The positive $\mathrm{u}-\mathrm{s}$ (unemployment-sectoral dispersion) correlation could be capturing the effects of aggregate shocks instead of labor market turbulence. Abraham and Katz (henceforth, AK) put forward an incisive example. 


\section{GALLIPOLI, PELLONI Macroeconomic effects of Job Reallocations: A Survey}

They assume a simple two-sector economy such that the sector's trend growth rates and cyclical sensitivities are negatively correlated and the two sectors are of same size at the start: $\frac{N_{1 t}}{N_{t}} \simeq \frac{N_{2 t}}{N_{t}}=\frac{1}{2}$. The natural logarithm of employment responds to deviations of aggregate output, $Y_{t}$, from its trend value, $Y_{t}^{*}$, less in sector one than in sector two $\left(\gamma_{1}<\gamma_{2}\right)$ while the trend growth is relatively stronger in sector one $\left(\Gamma_{1}>\Gamma_{2}\right)$. Then, $s_{t}$ can be approximated by:

$$
s_{t}=\left|\frac{1}{2}\left(\Gamma_{1}-\Gamma_{2}\right)+\frac{1}{2}\left(\gamma_{1}-\gamma_{2}\right)\left(\Delta \ln Y_{t}-\Delta \ln Y_{t}^{*}\right)\right|
$$

Given the assumption $\left(\Gamma_{1}-\Gamma_{2}\right)>0$, during a recession, when $\left(\Delta \ln Y_{t}-\Delta \ln Y_{t}^{*}\right)<0$ (and unemployment is relatively high), $s_{t}$ will be relatively larger because $\left(\gamma_{1}-\gamma_{2}\right)<0$. The opposite will happen during an expansion when the values of $s_{t}$ will be relatively dampened down. The positive correlation between $s_{t}$ and unemployment changes $\left(\Delta U_{t}\right)$ can be seen by appealing to Okun's law: $U_{t}=\alpha+\theta\left(\ln Y_{t}-\ln Y_{t}^{*}\right), \theta<0$. Thus, $s_{t}=\frac{1}{2}\left(\Gamma_{1}-\Gamma_{2}\right)+\frac{1}{2}\left(\gamma_{1}-\right.$ $\left.\gamma_{2}\right) \frac{\Delta U_{t}}{\theta}$ would display a counter-cyclical behaviour driven by aggregate shocks. To overcome this identification problem, researchers have proposed procedures which can be set apart by their reliance on aggregate or micro-level data. Keeping this demarcation in mind, and following the historical development of the literature, we set off by discussing empirical studies using time series and aggregate data.

\section{Time Series Models of Sectoral Shifts}

The empirical literature on sectoral shifts was originally developed using time series aggregate data. Papers taking this approach can be grouped into five main categories:

1. the 'purging' approach, based on a decomposition of dispersion proxies into sectoral and aggregate components;

2. methods exploring the correlation between observed dispersion and vacancy rate;

3. methods using dispersion indexes based on stock prices or accounting data;

4. vector auto-regressive models, free of dispersion measures;

5. multivariate non-linear models.

We discuss each method in turn, starting from the so called purging methodology.

\subsection{Purging}

Purging Lilien's proxy of aggregate effects has been often suggested as an effective way to handle the observational equivalence problem. This practice amounts to filtering out aggregate effects either directly from the dispersion index (MPZ, 1995;1996) or indirectly from the employment growth rates used to construct the index (AK, 1984 and 1986; Neelin, 1987; Samson 1990). Despite its shortcomings this method has been commonly applied in 
sectoral shifts analysis because of its simplicity. Because of the observational equivalence problem, a statistically significant coefficient on a Lilien-style sectoral dispersion proxy would not necessarily corroborate the SSH. The purging methodology recommends the decomposition of the dispersion proxy $s_{t}$ into an idiosyncratic component and a component measuring the response to aggregate shocks. In general, to obtain residuals purged of aggregate influences, $s_{t}$ is regressed on a vector of aggregate variables $\tilde{z}_{t}$,

$$
s_{t}=\beta_{0}+\sum_{j=0}^{q} \beta_{j} \tilde{z}_{t-j}+v_{t}
$$

There is wide variation across papers in the choice of variables included in $\tilde{z}_{t}$. Some authors, like AK (1984;1986), Neelin (1987) and Samson (1990), use monetary aggregates while others like MPZ $(1995 ; 1996))$ resort to both real and monetary aggregates. The estimated residual $\hat{v}_{t}$ from equation (7) provides the purged component of $s_{t}$. The generated residual, supposedly driven only by reallocation shocks, is then used in an unemployment equation:

$$
u_{t}=\gamma_{0}+\gamma_{1} \hat{v}_{t}+\sum_{j=0}^{T} \gamma_{2 j} z_{t-j}+\xi_{t}
$$

As the choice of variables in $z_{t}$ and $\tilde{z}_{t}$ is at the discretion of the researcher, the problem of under/over-purging arises. Some authors, concerned with the potential omission of relevant aggregate components, choose to further smooth the estimated residual $\hat{v}_{t}$ before including it in the final unemployment equation. AK $(1984 ; 1986)$ epitomizes this approach. The first step of this careful purging is analogous to the previous procedure. For the employment growth rate of each sector they estimate equations of the form,

$$
\Delta \ln x_{i t}=\beta_{i 0}+\sum_{j=1}^{T} \beta_{i j} \tilde{z}_{t-j}+v_{i t}
$$

where $\Delta \ln x_{i t}$ is employment growth rate in sector $i$ at time $t$ and the vector $\tilde{z}_{t}$ consists only of a measure of unanticipated money growth. The generated sectoral residuals $\hat{v}_{i t}$ are then used to compute the weighted average residual for each period over the $N$ sectors of the economy :

$$
\bar{v}_{t}=\sum_{i=1}^{N}\left(\frac{x_{i t}}{x_{t}}\right) \hat{v}_{i t}
$$

In a standard purging procedure the generated variable $\bar{v}_{t}$ would be used as a measure of dispersion, albeit an imperfect one. AK choose instead to address the potential under-purging through the introduction of an extra step. They add the generated $\bar{v}_{t}$ as a regressor in a new set of sectoral employment equations:

$$
\Delta \ln x_{i t}=\gamma_{i 0}+\sum_{j=1}^{T} \gamma_{i j} z_{t-j}+\lambda_{i} \bar{v}_{t}+\varepsilon_{i t}
$$




\section{GALLIPOLI, PELLONI Macroeconomic effects of Job Reallocations: A Survey}

where the disturbances $\varepsilon_{i t}$ are assumed to follow an $A R(1)$ process. Using the results from this step, AK construct their purged measure of dispersion as: $S_{t}^{A K}=\sum_{i=1}^{N}\left(\frac{x_{i t}}{x_{t}}\right)\left(\frac{\hat{v}_{i t}}{\sigma_{e}^{2}}\right)$.

The extra purging is aimed at removing the component of the residuals $\hat{v}_{i t}$ which moves together with the average of the residuals. This approach, however, is open to the criticism of over-purging. Later work has stressed that no explicit rationale is provided to back up this extra cleansing of data. It rather seems that a researcher, when using a similar approach, would face a high risk of removing those sectoral shocks which have similar effects on the economy as a whole. For example, if the correlation between the sector specific disturbances $e_{i t}$ is different from zero, then a conspicuous part of the sectoral noise could be captured by the artificial regressor $\bar{v}_{t}$, since the correlation among sectoral shocks would look like an economy-wide oscillation.

These issues are connected to the lack of detailed and clear definitions of sectoral and aggregate shocks, a problem common to many other works in this field. If an aggregate shock is meant to have an homogeneous impact on the whole economy, then it becomes extremely difficult to distinguish it from highly correlated sectoral shocks. The potential drawbacks of over-purging or under-purging are common to the whole purging literature. The purging strategy, despite its popularity and practicality, is exposed to the criticism of fine-tuning. Empirical results will vary widely according to the choices made by the researcher in terms of filtering steps and variables included in the vector $\mathrm{z}_{\mathrm{t}}$. The use of different purging procedures looks decisive. As an example, consider the mild purging technique of Samson (1990) and the careful purging approach of Neelin (1987), which provide contrasting results for the Canadian labor market. Samson uses a measure which is not totally free of aggregate impulses and that is much more variable in absolute terms because it is not normalized by any variability measure. As shown by Pesaran and Evans (1984), the non-scaling of an index by a variance measure could enhance its relative statistical significance. In contrast, AK's and Neelin's measures are based on a set of assumptions which drastically reduce sectoral volatility. It is unclear whether the difference between under and over-purged indexes is due to their different treatment of aggregate impulses or, more mechanically, to the larger variability of the under-purged indexes.

Studies with purged indexes tend to reject the sectoral shifts hypothesis. Two exceptions are MPZ (1995;1996;1997) and Byun and Hwang (2006, BH06). MPZ introduce cointegration analysis to this area, modeling money supply explicitly and adopting a finer sector decomposition than Lilien's. Using US quarterly data over the 1960-1991 period they find a positive and significant relationship between the unemployment rate and both purged and non-purged dispersion proxies. Their follow-up studies (1996; 1997), using UK data, also lend support to the SSH. BH06 raise a different point, arguing that if the sectoral shocks' 
distribution is asymmetric, the shape of the distribution could significantly affect estimation results. BH06 extend Lilien's symmetric, mean-preserving flow model by allowing for asymmetric distributions where mean and variance are held constant. The outcome clearly shows that the skewness could be an important factor in explaining fluctuations in aggregate unemployment. Once a skewness measure is introduced into the models of Lilien and AK, BH06 show that the dispersion index and the skewness measure have, respectively, a positive and a negative effect on the unemployment rate, thus bearing out the SSH. Recent work by Panagiotidis and Pelloni (2013) pushes the idea of BH06 further as they test the impact of covariates on location and shape of the conditional unemployment distribution. Since the linear regression model can only identify the conditional mean response of unemployment, they fit a quantile regression of the unemployment equation (5) over the period 1948 to 2011. The purged dispersion proxy is significant only for relatively high values of unemployment (relative to its median) and it becomes insignificant when unemployment is low. Their analysis reveals significant asymmetries and is fully consistent with the SSH. Stressing asymmetries, alongside the non-directional nature of sectoral shocks, offers a possible way out of the observational equivalence cunundrum. Still, there is a need for a solid and agreed upon theoretical model of sectoral shifts to impose clear and testable restrictions. This is a limit for both the quantile and linear regression approaches.

\subsection{Sectoral Shifts and the Beveridge Curve}

Methods related to the unemployment-vacancy $(U-V)$ relationship, the so-called Beveridge curve, dominated the early debate on the SSH, see for example the pioneering effort by Medoff (1983). Figure 2 plots the Beveridge curve for the United States using the HelpWanted Index (HWI) and the unemployment rate. The HWI is obtained from Barnichon (2010) adjusted vacancy index and normalized by the labor force. In the right panel of the Figure the data is smoothed using the HP Filter; however, in the left panel we report the nonsmoothed version of the relationship, which reveals an inward shift of the Beveridge curve over time.

AK $(1984 ; 1986)$ first suggested the possibility of separating the effects of sectoral shifts from those of aggregate shocks by looking at the correlation between vacancies, $V$, and Lilien's dispersion index, $s$. If the observed dispersion has been brought about by reallocation shocks, then there must be a positive relation between $V$ and $s$. On the other hand, a negative correlation between $V$ and $s$ suggests that aggregate shocks are responsible for labor market dispersion. Put simply, if aggregate shocks were the relevant driving force we should have movements along the Beveridge curve (negative $\mathrm{U}-\mathrm{V}$ comovements), whereas if sectoral 


\section{GALLIPOLI, PELLONI Macroeconomic effects of Job Reallocations: A Survey}

shifts were the real source of increasing unemployment we should observe an outward shift of the curve (positive U-V comovements).

Figure 2: Beveridge Curve

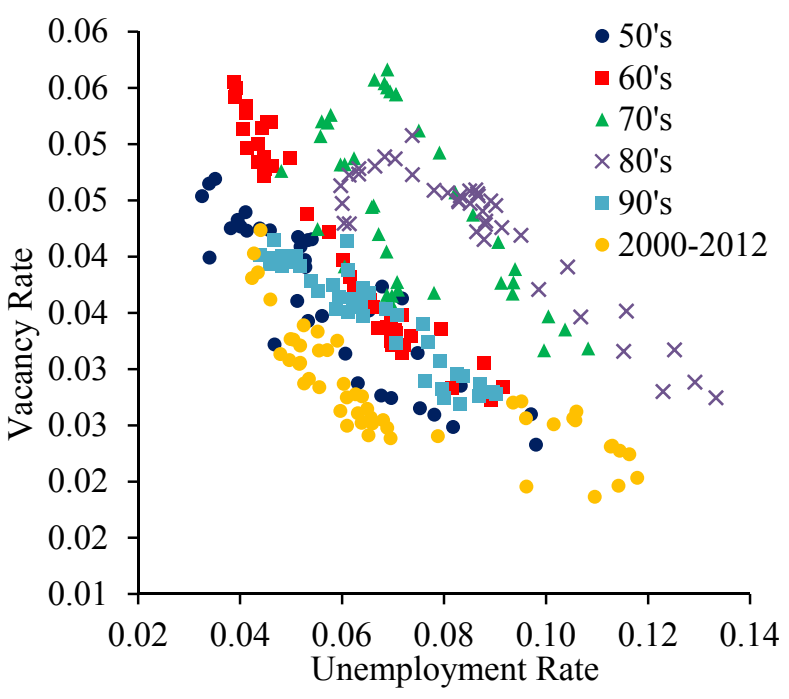

(a) Raw Data

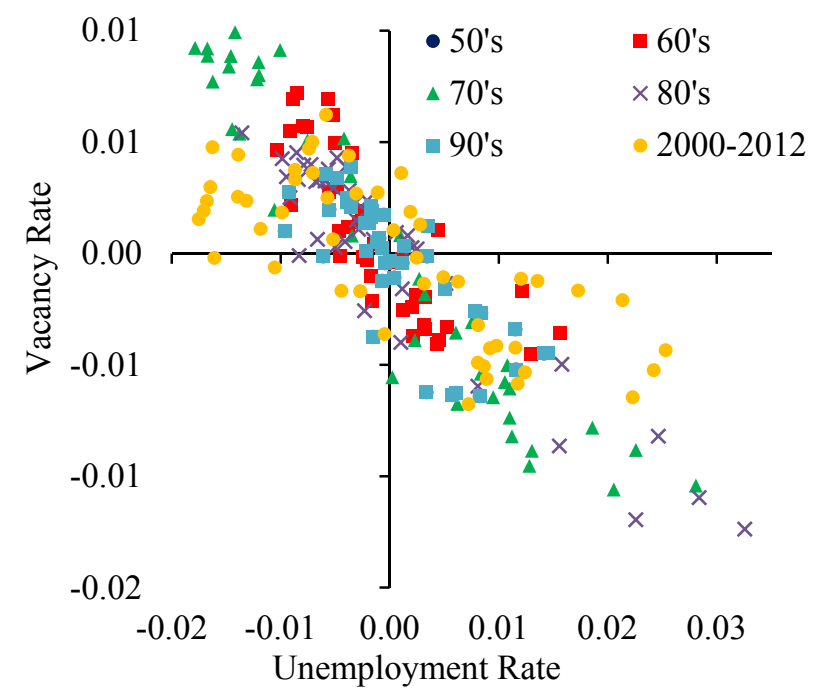

(b) Smoothed Data (HP Filter)

AK estimate the following linear vacancy equation using the help-wanted advertising index (HWI) as a measure of vacancies, $V_{t}=\pi_{0}+\pi_{1} s_{t}+\sum_{j=1}^{T} \pi_{2 j} z_{t-j}+e_{t}$, where $z$ is a vector of aggregate components, $s_{t}$ is the standard dispersion proxy as in (4), and $e_{t}$ is a white noise random process. In their analysis they argue that if $\pi_{1}$ were positive the sectoral shifts hypothesis would be corroborated, while if it were negative it would have to be rejected. Their findings support the latter result and have been subsequently corroborated by the work of Blanchard and Diamond (1989). Critics of the SSH have interpreted these results as strong rebuttals of the hypothesis, arguing that $\mathrm{V}-\mathrm{s}$ experiments are a procedure fully capable of discriminating between the two sources of unemployment fluctuations (see Johnson and Layard, 1986).

However the limitations of the U-V approach to the analysis of labor reallocations became apparent when Hosios (1994) clearly exposed a simple theoretical issue which undermines the view that only aggregate shocks are responsible for negative U-V comovements. In his paper 
Hosios develops an equilibrium matching model where reallocation shocks can induce a negative short term U-V relationship. He models some reallocation disturbances as changes in the relative dispersion of prices among firms. In this simple setup, a temporary relative price shock will induce $\mathrm{U}$ and $\mathrm{V}$ to move in opposite directions. The driving force in the model is an externality: the negative impact of temporarily laid off workers on job openings. It is more profitable for a firm to hire unattached workers than temporary layoffs since the latter have better outside options and demand relatively higher wages. A 'price-variance' shock which increases sectoral price dispersion will mechanically increase the number of searching workers. As the number of temporary layoffs increases, firms find it more difficult to spot unattached workers in the searching pool and are thus less willing to create new job openings. Since the number of searching workers is rising with fewer jobs available, the probability of finding a job decreases and therefore unemployment is increasing while vacancies are falling. Hosios' analysis implies that $\mathrm{U}$ and $\mathrm{V}$ data sets, in isolation, are unable to determine whether aggregate shocks or sectoral shifts are the main driving force behind aggregate unemployment fluctuations. In related work Palley (1992) argues that a negative U-V correlation is consistent with the SSH if it is costly to hire new workers. If hiring and firing costs are asymmetric, and hiring costs are higher than firing costs, sectoral shocks can generate movements along the Beveridge curve.

An additional issue with the U-V approach was pointed out by Davis (1987), who notices that the HWI, the vacancy proxy used by AK, is a stock value. Instead the appropriate variable for the experiment should be some vacancy rate whose behavior over the cycle differs from that of the vacancy stock. Since the pro-cyclicity of the HWI should be expected, as it largely reflects the search for temporary workers over the cycle, Davis argues that the results of AK do not provide strong evidence against the $\mathrm{SSH}$. With hindsight, it is fair to say that Hosios' results have set the tone of the discussion in this area for years. As long as U and $\mathrm{V}$ data are taken in isolation, regardless of the empirical setting, they may not provide the necessary information to sort out the SSH identification. This negative result has only recently been challenged in a rigorous framework by Mehrotra and Sergeyev (2012), whose work we discuss at the end of Section 6.4. For a further discussion of the U-V relationship we refer the reader to Diamond (2013).

\subsection{Stock Market Measures of Sectoral Shocks}

The indeterminacy associated with the empirical work based on Lilien's proxy prompted Loungani et al. (1991) and Brainard and Cutler (1993) to build indexes based on stock market data. Under the assumption of efficient markets, the behavior of an industry stock price is taken as a predictor of that industry's future fortunes. The key insight is that sectoral stock 


\section{GALLIPOLI, PELLONI Macroeconomic effects of Job Reallocations: A Survey}

prices reflect the discounted value of expected sectoral profits. Therefore the larger is the divergence in industries' fortunes, the larger will be the dispersion in sectoral stock prices. Forthcoming reshuffling of productive resources in the economy and higher unemployment should then be associated with greater dispersion in stock prices. An increase in the dispersion of stock prices would act as a leading indicator of unemployment. Furthermore, stock prices largely react to disturbances that are perceived to be permanent, which need not be true of observed sectoral employment changes.

This line of research spawned two new proxies, which we denote as $S W$ and CSV. Loungani et al. (1991), the earliest work in this field, construct their stock market dispersion measure by deflating yearly average indices of sectoral stock prices (a 45-sector decomposition) published by Standard and Poor's (S\&P's) and then calculate the $S W$ index:

$$
S W_{t}=\left[\left(\sum_{i=1}^{n} w_{i t}\left(R_{i t}-R_{t}\right)^{2}\right)\right]^{\frac{1}{2}}
$$

where $R_{i t}$ is the growth rate of stock prices for industry $i$ at time $t, R_{t}=R_{m t}$ is the return on the market portfolio at time $t$ (the average growth rate of stock prices based on the $S \& P$ 's data), $n$ is the number of sectors, and $w_{i t}$ is, as usual, sector $i$ 's employment share.

Estimation of a US unemployment equation a-la-Lilien, over the sample period 19311987, bears out the SSH. The lagged $S W$ covariates have the positive predicted sign and are statistically significant. These results are robust to alternative specifications and sample periods suggesting that the $S W$ measures may reflect inter-sectoral dispersion affecting unemployment. A first difficulty with this interpretation becomes apparent when decomposing sector $i$ 's return, $R_{i t}$, into a sector specific component and an aggregate component:

$$
R_{i t}=\beta_{i 0}+\beta_{i 1} R_{t}+\varepsilon_{t}
$$

If this holds the deviations of growth rates in (12) would also depend on $R_{t}$ because $R_{i t}$ $R_{t}=\beta_{\mathrm{i} 0}+\left(\beta_{\mathrm{i} 1}-1\right) \mathrm{R}_{\mathrm{t}}+\varepsilon_{\mathrm{t}}$. This observation highlights the possible presence of aggregate influences in the SW measure and is at the root of the following contribution by Brainard and Cutler (1993) (henceforth BC93).

BC93 argue for a theory-grounded approach, claiming that the CAPM model provides a theoretical basis for separating aggregate changes in stock prices from idiosyncratic movements. Under the efficient markets hypothesis, the arrival of information about the future profitability of a firm/sector would be captured in a single and immediate movement in its stock price, thus ensuring a tight temporal correspondence between the arrival of a shock and the response of stock market dispersion. Taking equation (13) as their starting point, BC93 construct a time series of the variance of sectoral stock market excess returns, which 
they call cross-section volatility, or $C S V$. This is defined as the weighted variance of onequarter excess returns, that is, $\operatorname{CSV}_{t}=\sum_{i=1}^{N_{t}} w_{i t}\left(\eta_{i t}-\bar{\eta}_{t}\right)^{2}$. In turn, the excess returns are defined as $\eta_{i t}=R_{i t}-\hat{\beta}_{1 i} R_{m t}=\hat{\beta}_{0 i}+\hat{\varepsilon}_{i t}$ and $\bar{\eta}_{t}$ is the average excess return and $w_{i t}$ is the usual weight. Since the unemployment equation is an unresolved issue, BC93 estimate several specifications of it using US quarterly data from $1948 Q 1$ to $1991 Q 2$. The empirical results confirm the statistical significance of reallocation shocks but also assign a minor role to them in explaining unemployment fluctuations. The innovation analysis shows that the impact on unemployment of a one-standard deviation shock to CSV is about $0.3 \%$ over a three year horizon. BC93 conclude that the overall effect of reallocation shocks on total unemployment, though statistically significant, have been mild. This is despite periods when the effects were substantial (e.g. CSV can account for $60 \%$ of the four percentage points increase in aggregate unemployment between 1973 and 1975). Other applications of the CSV dispersion proxy tend to corroborate BC93's findings (see Brainard (1992), Caporale et al. (1996), Fortin and Araar (1997) and the overview in Table 1).

Later work by Chen et al. (2011, CKLT11) revisits the analysis of Loungani and Trehan (1997) using more recent data including the 2001 and 2007-2009 recessions and finds that the effects of the $S W$ index are significant and substantial for the long-term behavior of unemployment, both in a single-equation approach (notable for including fiscal and monetary shocks, as specified by Romer and Romer (2004)) or as an outcome in a Choleski decomposition for a six-dimensional VAR. The VAR innovation analysis, with $S W$ ordered last, shows that about $25 \%$ of the variance of unemployment forecast errors is explained by innovations to $S W$ at a 5-year horizon. The fraction of explained variance is even higher for long-term unemployment, when innovations to the $S W$ index account for up to 40 percent of the overall variance (more than any other variable in the VAR). A robustness exercise carried out using Bloom (2009)'s uncertainty measure reveals that the latter can capture the behavior of short-term duration unemployment, but cannot explain the long term durations as, instead, $S W$ can. Overall, CKLT11 supports the view that cyclical factors appear more relevant for short-term unemployment dynamics (less than 5 weeks), but that the economic significance of the inter-sectoral dispersion proxy increases when the analysis shifts to the long run. The major drawback of CKLT11 is the use of $S W$ instead of $C S V$, which is more robust to contaminating aggregate influences.

One clear advantage of the whole approach based on stock market measures is that it explicitly introduces the informational role of prices in the SSH debate. The use of stockbased proxies brings this role to the fore by appealing to the Efficient Market Hypothesis, or EMH. This is clearly a merit of this line of research, but it also makes it dependent on the validity of the EMH. The EMH is itself at the centre of an unsettled debate - see Shiller 


\section{GALLIPOLI, PELLONI Macroeconomic effects of Job Reallocations: A Survey}

(2005; 2008) - and under severe scrutiny. Should the EMH be discarded or reduced in scope, then stock market measures, at least in their current shape, would be harder to justify.

Another major concern, whether one uses $S W$ or $C S V$, is that all these indexes may capture variations in the expected value of physical capital that are unrelated or inversely related to the expected value of human capital. It would then be possible for a firm to have contemporaneously positive excess returns and zero or negative excess employment. To control for this possibility BC93 derive sectoral excess employment changes as measured by the residuals of sectoral employment growth rates' regressions on the growth rate of total employment. The generated residuals are summed over different time horizons ranging from one quarter to five years and, finally, regressed on the one-quarter excess return. The estimated coefficients indicate that excess returns significantly predict employment growth, although the effect is small: an industry with a $10 \%$ excess return is predicted to have additional employment growth of roughly $0.8 \%$ after two years. No incremental effect is registered after four years although the initial effect persists.

The above procedures do not provide conclusive evidence on the reliability of $\operatorname{CSV}$ as an appropriate proxy for human capital reallocation. Various episodes in the stock markets cast doubts on the predictive power of excess returns over sectoral employment rates. It has often happened that, as firms announced cuts in employees' payrolls, their share price would experience sudden upward jumps, as if such announcements were indication of higher future profits. We do not wish to probe further the rationale underlying this kind of stock market response, but we rather stress how it can be misleading for sectoral shifts' analysis. In fact such episodes provide examples in which the logical sequence advocated by BC93 is entirely subverted: an upward stock price jump in such episodes emerges in response to announcements of future lay-offs, thus perverting the supposed relation between excess returns and employment growth. Moreover, the chronological sequence would still imply a positive correlation between $C S V$ and unemployment, since the announced lay-offs are going to take place only in the future and therefore stock market turbulence will grow before a series of lay-offs. The timing can be deceiving and lead researchers to the wrong conclusions.

In summary, this strand of the literature provides an alternative and appealing way to proxy for sectoral shifts. However, these proxies may still suffer from aggregate influences like Lilien-type proxies. Nonetheless, it is difficult to escape the conclusion that stock prices and accounting data contain valuable information about sectoral shocks (especially about their long-run effects). Future empirical application would benefit from having a firmer foundation in theory to account for all confounding effects. 
Review of Economic Analysis 5 (2013) 127-176

Table 1. Sectoral shifts models and stock market dispersion proxies

\begin{tabular}{|c|c|c|c|c|c|}
\hline Papers & $\begin{array}{l}\text { Dispersion } \\
\text { Proxy }^{\mathrm{a}}\end{array}$ & $\begin{array}{l}\text { Type of } \\
\text { Model }^{\text {b }}\end{array}$ & $\begin{array}{l}\text { Estimation } \\
\text { Procedure }\end{array}$ & Data & $\begin{array}{l}\text { Sectoral } \\
\text { Shifts }\end{array}$ \\
\hline $\begin{array}{l}\text { Loungani et al. } \\
\qquad \text { (1991) }\end{array}$ & SW & URFE & OLS & $\begin{array}{l}\text { US stock prices 1931-1987 } \\
\text { (Standard and Poor's) }\end{array}$ & $\begin{array}{l}\text { Support for SSH using } \\
\text { the stock market } \\
\text { dispersion index }\end{array}$ \\
\hline $\begin{array}{l}\text { Brainard } \\
\text { (1992) }\end{array}$ & CSV & URFE & OLS & $\begin{array}{c}\text { UK stock prices 1920-1938 } \\
\text { (London and Cambridge Econ } \\
\text { Serv.) }\end{array}$ & $\begin{array}{l}\text { Support for SSH in UK } \\
\text { during interwar period. }\end{array}$ \\
\hline $\begin{array}{c}\text { Brainard and Cutler } \\
\text { (1993) }\end{array}$ & CSV & URFE, VRFE & OLS & $\begin{array}{l}\text { US stock prices 1948-1991 } \\
\text { (Standard and Poor's) }\end{array}$ & $\begin{array}{l}\text { SSH not rejected } \\
\text { but only small role in } \\
\text { unemployment } \\
\text { fluctuations }\end{array}$ \\
\hline $\begin{array}{l}\text { Caporale et al. } \\
\text { (1996) }\end{array}$ & $\mathrm{CSV}$ & URFE & VAR & $\begin{array}{l}\text { US stock prices 1948-1991 } \\
\text { (Standard and Poor's) }\end{array}$ & $\begin{array}{l}\text { SSH explains small } \\
\text { proportion of } \\
\text { unemployment } \\
\text { fluctuations. }\end{array}$ \\
\hline $\begin{array}{l}\text { Fortin and Araar } \\
\text { (1997) }\end{array}$ & CSV & URFE & OLS & $\begin{array}{l}\text { Canadian stock prices 1980-1993 } \\
\text { (Toronto Stock Exchange) }\end{array}$ & $\begin{array}{l}\text { Changes in unemployment } \\
\text { are induced by monetary } \\
\text { conditions (not by SSH). }\end{array}$ \\
\hline $\begin{array}{l}\text { Loungani and } \\
\text { Trehan } \\
\text { (1997) }\end{array}$ & SW & URFE & VAR & $\begin{array}{l}\text { US stock prices 1962-1995 } \\
\text { (Standard and Poor's) }\end{array}$ & $\begin{array}{l}\text { SSH explains a } \\
\text { significant proportion } \\
\text { of the variation } \\
\text { in unemployment. }\end{array}$ \\
\hline $\begin{array}{l}\text { Chen et al. } \\
\text { (2011) }\end{array}$ & SW & URFE & VAR & $\begin{array}{l}\text { US stock prices 1963-2010 } \\
\text { (Standard and Poor's) }\end{array}$ & $\begin{array}{l}25 \% \text { of unemployment } \\
\text { variance is explained by SSH. }\end{array}$ \\
\hline
\end{tabular}

(a) SW: Weighted standard deviation of the growth rate of the industries' stock prices; CSV: Cross section volatility. It is defined as the variance of the excess return of industries' stock prices relative to the market.

(b) URFE: unemployment reduced form equation; VRFE: vacancy rate reduced form equation.

(c) About $75 \%$ of the forecast error variance of unemployment is caused by cyclical factors such as, real GDP changes, monetary and fiscal policies, and the uncertainty effects defined by Bloom (2009).

\subsection{VAR Models of Job Reallocation}

The initial attempts to test the SSH heavily relied on the use of dispersion indexes to proxy for reallocation shocks. In this section we examine VAR modeling strategies devoid of these proxies and discuss the main advantages and limitations of this approach. The seminal contribution in this area comes from Long and Plosser (1987). They estimate a thirteen- 


\section{GALLIPOLI, PELLONI Macroeconomic effects of Job Reallocations: A Survey}

dimensional VAR using monthly data of sectoral outputs to test the multi-sectoral real business cycle (RBC) model of Long and and Plosser (1983). In that model independent productivity shocks across sectors can in principle capture co-movements in sectoral activities over business cycles. Their approach is to use factor analysis on the innovations to determine whether the co-movements in sectoral outputs are the result of a common aggregate shock or a set of independent sectoral disturbances. Their estimates suggest that aggregate shocks can explain less than half of the variance in aggregate productivity, leading to the conclusion that the explanatory power of common aggregate disturbances is significant but not too large. The methodological approach of their analysis has become popular in the literature and has been updated in line with recent developments of time series analysis. In the wake of Long and Plosser (1987) there is a strand of literature dealing with sectoral output models and using dynamic factor models, see Acconcia and Simonelli (2008), Foerster et al. (2008) and references thereafter. In this survey, however, we restrict our interest to VAR models of job reallocations.

\subsubsection{The Approach of Campbell and Kuttner}

Some of the earliest applications and discussions of structural VAR models (SVAR) in macroeconomics are due to Blanchard and Quah (1989) and Lippi and Reichlin (1993). Building on this work Campbell and Kuttner (1996) propose a SVAR method to identify aggregate and sector-specific impulses. Their methodological claim is that a SVAR approach can explicitly spell out any identifying assumptions while allowing for sensitivity analysis under alternative restrictions. As a starting basic structure Campbell and Kuttner (1996) use a bivariate VAR of the natural logarithms of manufacturing employment share, $w_{t}$, and aggregate employment, $x_{t}$. The manufacturing share variable implies a two-sector (manufacturing and non-manufacturing) decomposition of the whole economy. This decomposition relies on the observation that shifts between manufacturing and nonmanufacturing employment account for most of the cyclical variation in employment growth dispersion. Both variables follow integrated I(1) processes and are included in terms of first differences. ${ }^{2}$ Campbell and Kuttner (1996) so that the VAR representation is:

$$
\mathbf{y}_{t}=\mathbf{A}(L) \mathbf{y}_{t}+\varepsilon_{t}
$$

\footnotetext{
2 The manufacturing share variable is modeled as a unit root I(1) process despite being bounded between zero and one. Its variance cannot diverge being a normalized measure. The inclusion of this variable as an I(1) process might have unpredictable effects on the inference which is subsequently drawn. On the other hand it does not look reasonable to explain the variability of employment growth rate through movements in the levels of manufacturing share, as the unit root tests unequivocally indicate that the share process is integrated. This modelling issue remains unsolved.
} 
where $y_{t}=\left(\Delta x_{t}, \Delta w_{t}\right), \mathrm{A}(\mathrm{L})$ is a matrix of lag polynomials of order $p$ and $\varepsilon_{t}=u_{t}+v_{t}$ is a vector of white noise shocks consisting of two components: orthogonal aggregate shocks, $u_{t}$, and reallocation shocks, $v_{t}$. $A_{h k}(L)$ is a lag polynomial summarizing the effect over time of the $h^{\text {th }}$ variable on the $k^{\text {th }}$ variable and $A(0)$ would be the sub-matrix of the contemporaneous effects whose elements along the main diagonal are zeros $\left(a_{x x}^{0}=a_{w w}^{0}=\right.$ 0 ). Campbell and Kuttner impose identifying restrictions to recover the structural disturbances, since in the estimated standard form of (14) the elements of the VAR innovation vector would be mixtures of the structural disturbances. To generate orthogonalized estimated innovations corresponding to structural shocks Campbell and Kuttner assume a lower triangular sub-matrix $A(0)$ by setting $a_{x w}^{0}=0$, ordering aggregate employment ahead of manufacturing in a Wold-causal chain. These restrictions rule out contemporaneous effects of reallocation shocks on total employment and lead Campbell and Kuttner (1996) to find that reallocation shocks account for a large amount (59\%) of the variation in manufacturing employment, but can only explain a small fraction (approximately 6\%) of aggregate employment fluctuations. Furthermore, the contemporaneous and long-run sectoral responses to aggregate shocks are both positive and statistically significant, whereas the long-run aggregate employment elasticity with respect to sectoral impulses is not significantly different from zero.

The triangularization solves the identification problem and identifies a lower bound of the explanatory power of sectoral reallocation shocks but it does not have an obvious theoretical justification. Therefore they also adopt a second identification scheme which is non-recursive and grounded in long-run neutrality assumptions imposed on the total impact matrix (see Blanchard and Quah, 1989 and King and Watson, 1997). The long-run multipliers are defined as $\gamma_{x w}=\left[a_{x w}^{0}+A_{x w}(1)\right] /\left[1-A_{x w}(1)\right]$ and $\gamma_{w x}=\left[a_{w x}^{0}+A_{w x}(1)\right] /\left[1-A_{w x}(1)\right]$, under the assumption that aggregate shocks have no long-run effect on the manufacturing employment share (that is, $\gamma_{w x}=0$ ). This conjecture is consistent with the claim that aggregate shocks can bring about only transitory changes in the profitability of capital across sectors with no lasting effects on capital distribution. Under this restriction the results of the innovation analysis change dramatically. The estimates of $a_{x w}^{0}$ and $\gamma_{x w}$ are large and significant and bear out the short and long-run relevance of reallocation shocks. A $1 \%$ positive shock to the manufacturing share raises total employment by $0.5 \%$ within a month, and a permanent $1 \%$ shock raises total employment by almost $0.8 \%$ in the long-run. Reallocation shocks can account for over half of the variance of total employment (51\%), and for nearly all of the variance in manufacturing, result partly reminiscent of the findings by Long and Plosser. 


\section{GALLIPOLI, PELLONI Macroeconomic effects of Job Reallocations: A Survey}

Following Loungani (1986), Campbell and Kuttner also experiment with a third (nonrecursive) identification scheme on the assumption that changes in oil prices can affect total employment only to the extent that they generate inter-sectoral reallocations. The univariate auto-regression of the percentage change of crude oil price is used to augment the original bivariate VAR. The results under this last specification corroborate the findings obtained under the long-run restrictions. Robustness checks based on the estimation of a sevendimensional VAR confirm the importance of reallocation shocks: under a finer sectoral disaggregation sectoral shocks can account between $27 \%$ and $82 \%$ of the aggregate employment variance, depending on which structural restrictions are chosen. Crucially, when Campbell and Kuttner allow for intra-sectoral movements the relative importance of reallocation shocks for aggregate employment fluctuations increases.

There is no doubt that Campbell and Kuttner's paper represents a methodological breakthrough and their findings corroborate the view that aggregate fluctuations should be studied in conjunction with intra/inter-sectoral reallocations. Their results bolster the empirical relevance of labor reallocation for aggregate unemployment dynamics; yet they cannot settle the causality issue. Their major contribution, still very important, is that unemployment fluctuations and permanent changes in employment sectoral shares are statistically interdependent phenomena. One criticism to their approach concerns the well known limits of long-run identifying restrictions in SVAR modeling. Faust and Leeper (1997) argue that longrun neutrality restrictions are usually insufficient to draw reliable inferences and suggest that long-run zero restrictions be tied to a restriction on finite-horizon dynamics. If this extra constraint is not explicitly introduced one may have different reduced forms fitting the sample equally well and yet extrapolating to the infinite future in very different ways (that is, one may obtain different reduced form long-run matrices $A_{w_{i} x}$ ). This requirement is not met by Campbell and Kuttner (1996) since no restrictions are explicitly imposed on finite-horizon dynamics. In addition, there are no obvious reasons to prefer ampbell and Kuttner (1996)'s specification to any potential alternative.

A serious drawback of a different nature is Campbell and Kuttner's characterization of reallocation disturbances as having a directional (positive/negative) nature. Treating sectoral shocks in the directional way typical of aggregate shocks makes their work akin to Blanchard and Quah (1989). This sort of directional behavior is not consistent with the underlying economic hypothesis: sectoral reallocation shocks induce some industries to expand while others contract. These simultaneous sectoral contractions and expansions should generate a reallocation process which is followed by fluctuations in aggregate unemployment. The signdependence of reallocation shocks in Campbell and Kuttner, e.g. positive shocks involving higher employment, does not capture the 'size' of reallocation but the 'direction' of the 
shocks. Simply put, this account of reallocation disturbances misrepresents the impact channel of labor market turbulence. It is the magnitude of necessary reallocations brought about by an idiosyncratic shock, rather than the shock's direction, that determines the aggregate unemployment response. The idea that the shock's direction is not relevant for labor reallocation, while its size matters, suggests that the SSH could be naturally tested within a non-linear framework.

\subsubsection{Multivariate Volatility Models}

The linearity restrictions of Campbell and Kuttner (1996) are the starting point of Pelloni and Polasek (1999; 2003) who develop a multivariate GARCH in mean (VAR-GARCH-M) to examine whether volatile growth in sectoral employment shares has an impact on aggregate employment. Pelloni and Polasek (1999) formulate the SSH in terms of sectoral time series models containing volatility effects. The authors claim that current time series techniques open up the possibility of framing the SSH in a richer dynamic dimension without appealing to ad-hoc dispersion measures. They point out that Lilien's net hiring function (1) can be generalized through an explicit heteroscedasticity assumption on $\varepsilon_{i t}$, the sector specific hiring shock:

$$
\begin{aligned}
& \varepsilon_{i, t}=u_{i, t}\left(h_{t}^{i}\right)^{1 / 2} \\
& h_{i t}=\alpha+\sum_{j=1}^{q} \theta_{j}^{i} \varepsilon_{i, t-j}^{2}
\end{aligned}
$$

with $u_{i, t} \sim$ iid $N(0,1)$ and $h_{i t} \equiv \operatorname{Var}\left(\varepsilon_{i, t} \mid I_{t-1}\right)$ while equation (15) is the ARCH generating process of the sector specific component in equation (1).

In principle, the $\mathrm{ARCH} / \mathrm{GARCH}$ representations of the shocks can be seen as reasonably akin to Lilien's original claim of heteroscedasticity. In operational terms this idea is implemented via a multivariate GARCH in mean (VAR-GARCH-M) model of the growth rates of aggregate employment and of sectoral employment shares. If we denote the sectoral shares' vector as $y_{t}$, Pelloni and Polasek's VAR representation is: $y_{t}=A(L) y_{t}+B(L) h_{t}+$ $\varepsilon_{t}$, where $B(L)$ is a lag polynomial, $h_{t}$ a vector of conditional variances and $\varepsilon_{t}$ a vector of mutually and serially uncorrelated random errors. According to this specification the conditional means are functions of the contemporaneous and lagged values of the conditional variances. The estimated conditional variances are interpreted as measures of actual reallocations and the $B(L) h_{t}$ component represents how the measured volatilities (i.e. the effective reallocations) feed back into the means (aggregate employment and sectoral employment growths). Furthermore, as shocks could display a time-changing (conditional) variance, with larger past shocks implying larger current volatility, there could be an error- 


\section{GALLIPOLI, PELLONI Macroeconomic effects of Job Reallocations: A Survey}

clustering effect consistent with the maintained economic hypothesis of sectoral shifts. The SSH can reasonably encompass an arrival process of information, reflecting changes in sector-specific fundamentals, reaching a sector in clusters. In this case, reallocation shocks may present a profile of persistent volatility changes whereby a large shock tends to be followed by another large shock. Such persistent effect can be enhanced also by the dynamic market response to incoming news.

Pelloni and Polasek (1999) apply a five-dimensional model to US quarterly series between 1975 and 1990. They find that both aggregate and sectoral volatilities have a role, though the latter seem to have a larger one. A variance decomposition analysis, carried out by imposing a Choleski factorization, finds that, with a year-ahead forecast horizon, sectoral innovations account for $65 \%$ of the aggregate employment variance, whereas aggregate innovations cannot explain more than $28 \%$ of the sectoral variances, regardless of the forecast horizon. This is a surprising result since aggregate employment is ordered ahead of sectoral shocks so as not to allow contemporaneous effects of reallocation shocks over total employment growth. This triangularization is analogous to the first set of restrictions of Campbell and Kuttner (1996) and provides a lower bound estimate of the contribution of sectoral shocks to the explanation of total employment variance. Reallocation shocks, though embedded in an unfavorable specification, have a large and significant role in explaining aggregate employment behavior. In comparison with Campbell and Kuttner (1996) these results provide stronger evidence in favor of reallocation shocks or, at least, stress even more the interdependence between aggregate fluctuations and reallocation. The GARCH structure seems to capture important features of the system's dynamics, reinforcing the role of sectoral disturbances.

Pelloni and Polasek (2003) and Panagiotidis et al. (2003) further corroborate the evidence in favor of sectoral shifts by looking at other countries besides the US. In general, this line of work extends Campbell and Kuttner (1996) by explicitly allowing the dispersion of sectoral shocks to affect conditional means. This result is achieved without resorting to generated regressors and constructed dispersion indexes. Yet, this approach suffers from a clear overparameterization problem. An example is Pelloni and Polasek who, given their small sample (quarterly data for 15 years), end up having slightly more than one observation for each parameter. As pointed out by Harvey et al. (1994), although the multivariate GARCH model could be estimated efficiently by maximum likelihood, the number of parameters can be so large that it is necessary to impose restrictions. Pelloni and Polasek do not mention this problem and all the restrictions they try to impose are statistically rejected in favor of the unconstrained model. The idea of imposing a non-linear structure on a VAR which can capture inter-sectoral reallocations and feed them back into the means is coherent with the 
Review of Economic Analysis 5 (2013) 127-176

SSH and empirically plausible, however data limitations pose a serious constraint on this approach.

\subsubsection{A Regime Switching Model of Sectoral Shifts}

The non-linearity in unemployment responses to reallocation shocks, which we highlight in the previous sections, is a characterizing attribute of the SSH. Storer (1996) exploits this feature by looking at the effects of natural resource shocks on the labor markets of two very different Canadian provinces, Ontario and Alberta. The province of Alberta is a net producer of natural resources and the production of petroleum and natural gas is paramount for its economy. In contrast, Ontario is a manufacturing province and a net energy user. Thus oil price shocks should set these two provinces on opposite paths: the oil price rises of 1973 and 1979 should favor Alberta while the 1986 price crash should bring about a reverse of fortunes. From the equilibrium solutions of a fairly standard search model, Storer defines the recruitment intensity equations for each province and then conducts a shock decomposition exercise by means of a Markov-switching regression model. He uses this method to capture regime shifts induced by natural resource shocks like the oil price shocks of the 1970's and 1980 's, as well as by aggregate shocks. Based on quarterly data on labor market tightness in Alberta and Ontario during the period 1966-1998, his analysis suggests that aggregate shocks are of paramount importance for Alberta, while in Ontario the two types of shocks have had effects of similar sizes. Shocks persistence is pervasive and both aggregate disturbances and sectoral shocks have lasting effects. Storer's approach is rich in methodological insights and it is surprising that it has not been taken up and carried further by other authors. The use of a quasi-natural experiment, in conjunction with a methodology which allows to capture the non-linearity of the responses to reallocation shocks, seems to be a promising strategy.

\section{Job Creation and Job Destruction Models}

The literature on job creation and job destruction (JC and JD) provides an alternative set of tools to explore the nonlinear responses to reallocation shocks. Because vital information may be lost by looking at employment dispersion (or proxies of it) across highly aggregated sectors of the economy, it may pay large dividends to explore finer sectoral subdivisions or intra-sectoral movements. The JC\&JD line of investigation has been made possible by the increasing availability of new and accurate data sets. Its influence and importance for both business cycle analysis and economic growth cannot be overstated. In this survey we limit our attention to that part of the JC\&JD literature which has dealt directly or indirectly with the observational equivalence problem of reallocation shocks. 


\section{GALLIPOLI, PELLONI Macroeconomic effects of Job Reallocations: A Survey}

\subsection{Measuring Job Flows}

The pioneering work of Davis and Haltiwanger (1992; 1999) and Davis et al. (1996) proposed the notions of job creation (POS) and job destruction (NEG) as the underpinnings for the organization, measurement and analysis of the information extracted from the Longitudinal Research Database (LRD) at the Center for Economic Studies of the US Census Bureau. The LRD is a panel data set gathering employment data at annual and quarterly frequencies for each plant in the panel.

Let POS denote the employment gains summed over all plants that expand or start up between periods $t-1$ and $t, P O S_{t}=\sum_{e \in S^{+}} X_{e s t}-X_{e s t-1}$. Similarly, let NEG is the sum in absolute value over the employment losses of the plants that contracted or were shut down between periods $t-1$ and $t, N E G_{t}=\left|\sum_{e \in S^{-}} X_{e s t}-X_{e s t-1}\right|$. An employment position filled by a worker is denoted by $X$ and the subscripts $e, s$ and $t$ indicate establishment/plant, sector and time period, respectively. If $S$ is the reference sector (e.g. US manufacturing) then $S^{+}$is the subset of plants in $S$ that are expanding or starting up, while $S^{-}$is the subset of the contracting or closing up plants. Using the above variables, we can define: (i) net job creation, as $N E T_{t}=P O S_{t}-N E G_{t}$; (ii) gross job reallocation, as $S U M_{t}=P O S_{t}+N E G_{t}$; and (iii) excess job reallocation, as $E X C_{t}=S U M_{t}-\left|N E T_{t}\right|$. So far all the definitions refer to job reallocations as opposed to worker reallocations. ${ }^{3}$ Davis et al. (1996) detect four major stylized facts characterizing job flow data: (i) gross flow rates are large at all times; (ii) the cyclicality of POS and NEG brings about a counter-cyclical SUM, since during recessions NEG increases sharply, while POS decreases relatively little or even increases; (iii) most job reallocation is persistent or permanent; (iv) job flows are concentrated in a relatively small number of establishments.

These empirical traits, together with other features (for a discussion see Schuh and Triest, 1998), provide a basis for imposing restrictions on the empirical analysis of the effects of job reallocations. A substantial literature has followed these seminal contributions. Evidence suggests that, within manufacturing, there exists a negative correlation between job reallocation and employment growth and that JD varies more than JC over the cycle. Baldwin et al. (1998) show that 1 in 10 manufacturing jobs are created and destroyed every year and

${ }^{3}$ A link between job and worker reallocations clearly exists and can be formalized by defining gross worker reallocation at time $\mathrm{t}$ as the number of people who change place of employment or employment status between $\mathrm{t}-1$ and $\mathrm{t}$. The amount of worker reallocation induced by job reallocation can at most equal SUM but cannot be smaller than the largest value between POS and NEG. These definitions provide both an upper (SUM) and a lower (the larger between POS and NEG) bound on the amount of worker reallocations. All these definitions can be expressed in terms of rates instead of levels, (see Davis et al. (1996)). 
that JD is more volatile than DC over the period 1972-1993 both in Canada and US. Foote (1998) argues that this result may be specific to declining sectors such as manufacturing. He uses manufacturing and non-manufacturing data collected by the Michigan State Unemployment Insurance System over the period 1978-88. He develops a $(S, s)$ model to derive a testable form linking the standard deviations of JC and JD to the relative means of the job flows of a specific industry. He finds that for growing sectors JC is relatively more volatile than JD. Davis and Haltiwanger (1999) extend and complement the LRD series with data drawn from the Bureau of Labor Statistics (BLS). The sample consists of quarterly time series data for the manufacturing sector covering the period 1947:1 to 1993:3. Their benchmark SVAR model is estimated and tested by imposing restrictions defined accordingly to the diverse POS and NEG dynamics brought about by aggregate and reallocation shocks. Letting $y_{t}=\left(P O S_{t}, N E G_{t}\right)^{\prime}$, Davis and Haltiwanger (1999) suggest a bivariate VAR(p) of the form $y_{t}=A(L) y_{t}+\varepsilon_{t}$. Here $A(L)$ denotes a p-order matrix lag polynomial which can have a linear $M A(\infty)$ representation

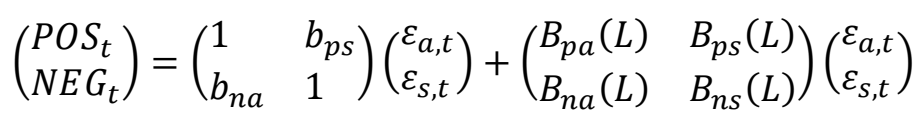

where $B_{h k}(L)^{\prime} s$ are lag polynomials and $\varepsilon_{t}=\left(\varepsilon_{a t}, \varepsilon_{s t}\right)^{\prime}$ is a vector of structural orthogonal disturbances. The estimated unrestricted VAR would yield an $M A(\infty), y_{t}=D(L) \eta_{t}$, ${ }^{4}$ whose vector of innovations, $\eta_{t}$ does not necessarily coincide with the vector of structural shocks, $\varepsilon_{t}$, as each of its elements would be a mixture of the elements of $\varepsilon_{t}$. To identify the impact of the shocks Davis and Haltiwanger (1999) impose restrictions capturing the directional and symmetric effects of aggregate shocks vis-a-vis the asymmetric and non-directional nature of reallocation shocks. An aggregate shock would cause POS and NEG to move in opposite directions (a negative aggregate shock would simultaneously reduce POS and increase NEG) while a reallocation shock would induce POS and NEG to move in the same direction. The coefficients of the sub-matrix $B(0)$ which captures the contemporaneous responses of NEG to aggregate shocks and of POS to reallocation shocks are restricted to be negative and positive respectively, $b_{n a}^{0}<0, b_{p s}^{0}>0$. These two restrictions, together with $\operatorname{cov}\left(\varepsilon_{a t}, \varepsilon_{s t}\right)=0$, introduce a set of " weak" restrictions which, though not capable of exactly identifying the structural parameters, can restrict their range of permissible values and generate qualitative identifying information with strong economic significance. To narrow further the structural parameters range and generate more precise inference, Davis and Haltiwanger impose tighter

${ }^{4} D(L)$ being an infinite-order matrix lag polynomial of estimated coefficients. 


\section{GALLIPOLI, PELLONI Macroeconomic effects of Job Reallocations: A Survey}

inequality conditions which emerge from recent theories of POS and NEG dynamics. They can be summarized as follows:

1. $\mathbf{b}_{\mathbf{n a}}^{\mathbf{0}} \leq \mathbf{- 1}$. This restriction states that an aggregate shock would bring about a NEG response at least as large as a POS response. Theoretically this claim can be based on the reallocation timing hypothesis of Davis (1987) or, alternatively, on search and matching models (see Mortensen and Pissarides, 1999). An aggregate negative shock, under the reallocation timing hypothesis, would lead to reallocation bunching during a recession. In a search model, it would generate an asymmetric response in NEG and POS dynamics (NEG rises more rapidly than POS because of the sluggishness brought about by the matching process).

2. $\left|\mathbf{b}_{\mathbf{p s}}\right| \leq \mathbf{1}$. This assumption asserts that the contemporaneous response of POS to a reallocation shock is smaller in magnitude than the contemporaneous NEG response. From a theoretical point of view this restriction has two justifications. First, the inherent asymmetry between the matching and separation processes induced by the instantaneousness of job separations and the time-consuming nature of matching, as in Pissarides (1985) and Mortensen and Pissarides (1994). Second, the potential presence of an 'option value effect' which could boost the waiting time of employers and employees in response to sunk costs associated with the creation of new vacancies and job matching Davis and Haltiwanger (1992).

3. $\sum_{\mathbf{l}=\mathbf{1}}^{\mathbf{m}} \mathbf{B}_{\mathbf{p s}}(\mathbf{l})>\mathbf{0} \quad \forall \mathbf{m}$, s.t. $\mathbf{2} \leq \mathbf{m} \leq \mathbf{M}<\infty$. The third and last restriction states that reallocation shocks would ultimately raise job creation.

Davis and Haltiwanger (1999) also impose restrictions on the total impact matrix in the fashion of Blanchard and Quah (1989) and King and Watson (1992). Their findings cannot isolate the relative importance of aggregate and reallocation shocks. Inference about the impact of different kinds of shocks are very sensitive to the nature and type of adopted restrictions. The mechanics of job creation represent the focus of Caballero et al. (1997), who provide a micro-foundation for aggregate employment dynamics based on adjustment costs and a combination of aggregate (common-across-plants) and idiosyncratic (plant-level) shocks. Changes in the variance (and higher moments) of the plant-level shocks are interpreted as reallocation shocks. Using quarterly, plant-level data for the US manufacturing sector between 1972 and 1980 from the LRD, Caballero et al. find that about $90 \%$ of the fluctuations in microeconomic adjustment accounting for changes in average employment growth are driven by aggregate, rather than reallocation, shocks. Aggregate shocks are assumed to be the cross-sectional average of plant level shocks. 


\subsection{Job Flows in the Long-Run and over the Business Cycle}

Davis and Haltiwanger (1999) bring to the fore the non-linear effects of reallocation shocks and suggest a coherent methodological structure on which to build a new research agenda aimed at shedding light on puzzling stylized facts of both long-term trends and business cycle fluctuations. The first set of contributions, such as Faberman (2006) and Davis et al. (2006) and Davis et al. (2008), focuses on a secular decline in business-level volatility. For the first time new data sources are introduced into this field. One is the Business Employment Dynamics (BED) from the BLS and the Longitudinal Business Database (LBD) from the Census Bureau, which covers the whole private sector of the US economy.

Faberman (2006) exploits the BED to challenge the conventional wisdom about the business cycles being driven by a raise in JD. Using manufacturing data dating back to 1947, F06 shows that the slow labor market recovery associated to the 1990-92 downturn was due to a relatively slow decline in JD, while, after the 2001 recession, there was a decline in JC (larger relative to the increase in JD) coinciding with a decrease both in magnitude and volatility of job reallocation. Davis et al. (2006) find a large secular decline in the crosssectional dispersion of business growth rates and in the time-series volatility of growth rates at firm level (data from the LBD and Compustat from 1976 to 2001). Analyzing privately held firms and publicly traded firms separately they confirm that the rise in volatility among the latter is overwhelmed by declining volatility among privately held firms. If firm volatility is interpreted as a proxy for the intensity of reallocation shocks, a lower intensity of firm volatility would result in less job loss, smaller unemployment inflows and outflows rates, and less frictional unemployment.

Working along similar lines, Davis et al. (2008) find compelling evidence that the intensity of idiosyncratic labor demand shocks has a large and positive effect on the incidence of unemployment. In a related paper, Groshen and Potter (2003) discuss the 'jobless recovery' of 2002-2003. The authors divide recessional adjustment into two components: cyclical and structural adjustments, where cyclical shocks are temporary and structural shocks are permanent. They examine the importance of temporary layoffs by tracking this measure over the past six recessions. They find that during the recoveries of 1991-1992 and 2002-2003 structural shocks were prevalent (and probably due to reallocation shocks), while temporary layoffs increased little in 1991-1992 and barely rebounded in 2002-2003. These findings are challenged by Rissman (2003) and Aaronson et al. (2004). The first paper analyzes the annualized quarterly employment growth net of aggregate employment growth by industry from 1954 to 2003. The sectoral classification is based on NAICS with the exclusion of mining. By controlling for the idiosyncratic responses to the 'common' component in employment fluctuations through time dummies the author argues that sectoral reallocation 


\section{GALLIPOLI, PELLONI Macroeconomic effects of Job Reallocations: A Survey}

shocks were not unusually large, by historical standards, during the most recent recessions. An important assumption in Rissman (2003) is that the 'cyclical' component of employment growth is industry-specific: the author argues that this assumption is reasonable because aggregate cyclical fluctuations impact each industry differently. However, by interpreting all sector-specific time-effects as aggregate fluctuations, this procedure runs the risk to partly underestimate sectoral shocks' relevance. In a follow-up paper, Aaronson (2004) argue that the fall in the proportion of the unemployed on temporary layoffs during the 2001 recession is not large enough to explain a major portion of the decline in post-recession employment growth. On the flip-side these authors also claim that the increase in the share of unemployed labor force because of permanent layoffs was not high, by historical standards, during that period.

\subsection{Using Real Exchange Rates to Identify Sectoral Reallocation}

Some researchers have proposed to use real exchange rate fluctuations as a proxy of demand shocks which force a labor reallocation across sectors with different exposure to international competition. This is yet another way to resolve the fundamental identification problem and to distinguish between reallocation and aggregate shocks. A significant contribution in this direction is due to Gourinchas (1998). Adopting a classification based on export shares and import penetration ratios, the author uses real exchange rates variation to identify the effects of sectoral shifts on gross and net job reallocations within the US manufacturing industry. ${ }^{5}$ Industries are grouped into two categories: the first includes industries open to international competition (tradable sector), while the second consists of industries which do not export nor compete with foreign firms in the domestic market (non-tradable sector). Under the initial assumption that real exchange variation can be considered exogenous for individual firms, the author uses it to identify changes in the relative demand of goods in different sectors. He confirms previous findings by Davis and Haltiwanger (2001) and documents that both JC and JD grow in response to a reallocation shock (i.e., an appreciation of the real exchange rate). This positive comovement contrasts with the diverging responses of job creation and destruction to aggregate shocks. The latter results appear partly at odds with evidence presented by Davis et al. (1996), who remark on the striking absence of a systematic relationship between the magnitude of gross job flows and exposure to international trade. Yet, the fact that, following an exchange rate shock, job creation and destruction move in the same direction is evidence of pure reallocation shocks, which induce simultaneous increases in both JC and JD. The main contribution of this analysis is to convincingly show that

\footnotetext{
${ }^{5}$ Job flows are measured, like in Davis and Haltiwanger (1990), using sectoral data on job creation and destruction for both 2-digit and 4-digit industries in the Census LRD 
exchange rate swings can be useful to pinpoint historical episodes characterized by sectoral labor reallocation. While this particular application uses US data, the identification method seems more promising for small open economies, such as those of many European countries, where exchange rate fluctuations might be enough to induce relatively large sectoral shifts.

Some of the findings of Gourinchas are confirmed by Klein et al. (2003) who document the significant effect real exchange rates have on JC and JD in US manufacturing industries between 1973 and 1993. Also Haltiwanger et al. (2004) use harmonized measures on job creation and destruction for various countries in Latin America to investigate the impact of trade openness on net employment and gross job reallocation. They find that reductions in tariffs and exchange rate appreciations increase the pace of job reallocation within sectors; however the effects are not very large during the period under examination. ${ }^{6}$

\section{Other Research Based on Micro-Data}

The pessimism surrounding the ability of existing models to address the observational equivalence problem when testing the SSH led economists to look for evidence in micro (individual-level) data. Micro-data offer a wealth of information on individual job market behaviors and inter-industry mobility, both of which are the very essence of the SSH. The seminal contributions in this area are those of Murphy and Topel (1989), Loungani et al. (1989), and Loungani Rogerson (1989). All these studies try to determine the fraction of total unemployment explained by two classes of workers: unemployed workers changing sectors (switchers) and those who remain in the same industry (stayers). Murphy and Topel (1989) strongly reject the SSH while Loungani et al. (1989) and Loungani and Rogerson (1989) find support for it. Such contradictory conclusions arise because of differences in the definition of industry switching and the structure of the data (panels vs cross-sections).

Unlike Murphy and Topel who use the CPS, ${ }^{7}$ Loungani et al. (1989) and Loungani and Rogerson (1989) use the PSID. ${ }^{8}$

${ }^{6}$ For a survey of the literature regarding the relationship between international trade and job flows see Klein et al. (2002).

${ }^{7}$ The CPS contains cross-sectional individual data on prime-age males drawn from the Annual Demographic File (the March Survey). Each March Survey file contains individual information on current labor force status, industry and occupation; it also gathers retrospective information on industry and occupation of longest job held during the previous calendar year and on unemployment during the last calendar year. The CPS does not follow individuals over time, therefore the collected individual information applies to a fifteen-month period at most.

${ }^{8}$ In the PSID individuals are interviewed in the Spring of each year. Data on current employment status, occupation and industry and weeks of unemployment experienced during the last calendar year are collected. Although the CPS presents advantages in terms of size, it cannot provide a work history of the interviewees as the PSID does. 


\section{GALLIPOLI, PELLONI Macroeconomic effects of Job Reallocations: A Survey}

Their definitions of industry switching are also very different. Murphy and Topel do not include unfinished unemployment spells among sector switches, whereas Loungani et al. and Loungani and Rogerson denote as 'switchers' those individuals who do not return to their original industry within two years of the switch. Given their definition of sector mobility Murphy and Topel find that 'switchers' account on average for $24 \%$ of total unemployment. Moreover, this share is virtually constant over the period 1970-1985, while total inter-sectoral mobility is strongly pro-cyclical and tends to be higher when unemployment is comparatively low. Therefore, Murphy and Topel conclude that unemployment fluctuations are explained by 'stayers', who account for the bulk of total unemployment.

Loungani et al. argue that Murphy and Topel's findings rely heavily on their definition of inter-sectoral mobility. When Loungani and Rogerson adopt Murphy and Topel 89's definition of industry switching to analyze their PSID sample, they draw (at least qualitatively) conclusions similar to those of Murphy and Topel's. However, when they use their own definition of 'switchers' on the same sample, the results change dramatically. Under Loungani and Rogerson's definition, switchers account for approximately $25 \%$ of total unemployment during expansions and nearly $40 \%$ during recessions. The results obtained under different definitions of mobility are clearly in conflict.

Starr-McCluer (1993) discusses the methodological issues underlying these contradictory outcomes. Murphy and Topel ignore that: (i) censored spells often end with a sectoral switch; (ii) censored spells increase in relative importance during recessions. If inter-sectoral job changes include only complete switches, like in Murphy and Topel (1989), then a pro-cyclical bias is introduced because transition spells last longer during recessions and are more likely to be censored. This means that the contribution of 'switchers' to total unemployment is underestimated during recessions.

On the other hand, a counter-cyclical bias characterizes Loungani and Rogerson's methodology. Though censored spells are a small share of their sample, they account for a large fraction of unemployment. For these reasons Starr-McCluer chooses to use competingrisks transition analysis to address the censored spells problem. This approach is appropriate for duration models in which spells can end into a set of possible different states. Thus it should be able to differentiate between transition into similar and different jobs (see Lancaster, 1979). Applying her methodology to a sample from the PSID, she obtains results suggesting a negative duration dependence of transiting from unemployment to a job in the original sector (from a 0.24 probability at the beginning of the spell to a 0.11 probability after 
9 months), whereas the hazard to work in a different sector increases with spell duration (from a 0.02 to a 0.09 probability after 9 months). As a consequence, while the spell unfolds, the probability of it ending in re-specialization (i.e. transition to a different sector) rises. It is very important to notice that this hazard becomes roughly constant after 9 months (partly due to the very small number of spells still in progress beyond such time) and that fairly long spells have a 50-50 chance of ending with a return to similar work. Starr-McCluer argues that, after controlling for individual characteristics, workers who become unemployed during recessions are more likely to re-specialize. A one-tenth of a percentage point decrease in national unemployment has an extremely strong effect on workers from the manufacturing and construction sectors: the hazard of exiting into similar jobs would rise by $5.5 \%$, whereas the hazard of exiting into different jobs would rise by $24.1 \%$. Starr-McCluer notices that “...while spells beginning in recession were unusually likely to end in re-specialization, transitions into new industries or occupations accelerated with recovery, not when recession was ongoing. This probably contributes to the contradictory results of Murphy and Topel and Loungani and Rogerson...". Overall, the results of Starr-McCluer support the sectoral shifts hypothesis. She finds that the share of unemployment associated with respecializations rises from $28 \%$ in expansions to $34.5 \%$ in recessions.

Also Thomas (1996) takes a skeptical view of the Murphy and Topel's findings: he observes that 'switchers', despite constituting a small fraction of the unemployed, can still play a substantive role if they form a sufficiently large proportion of the long-run unemployed. Thomas (1996) uses the 1986 wave of the 'Labor Market Activity Survey' for Canada and provides evidence that 'switchers' experience indeed longer spells of unemployment. He also uses competing-risks duration models that can distinguish among sectoral re-employment outcomes.

An interesting contribution in this area comes from Shin (1997), who brings together the micro-data approach and the dispersion index literature. He uses US accounting data from the Compustat database on publicly traded companies to compute sectoral dispersion measures. Sectoral shocks are approximated by the dispersion of sectoral returns to physical capital under the assumption of complementarity between capital and labor. Alongside this dispersion index across industries ('ACROSS') he also computes a dispersion index within industries ('WITHIN') using the 20 manufacturing industries defined by 2-digit standard industrial classification (SIC) codes. Following the job creation and job destruction literature the WITHIN measure is adopted as a proxy for intra-sectoral shocks. The ACROSS index is purged of aggregate effects using the filtering methodology proposed by AK. Shin runs several regressions of the aggregate unemployment rate on both indexes and other variables controlling for aggregate monetary and real shocks. He finds that, although the magnitude of 


\section{GALLIPOLI, PELLONI Macroeconomic effects of Job Reallocations: A Survey}

intra-sectoral shocks is larger than that of inter-sectoral shocks, the latter is the only variable which can explain the dynamics of aggregate unemployment. Shin's procedure to purge the dispersion index is similar to that of $\mathrm{AK}$ and the critiques moved to their work can be extended to Shin's. It is also unclear why the measure of intra-sectoral reallocation (WITHIN) is not filtered of aggregate components as its inter-sectoral counterpart (ACROSS).

In our discussion we follow Neumann and Topel (1991) that is pivotal to the development of micro-data modelling because of its huge influence on subsequent work. Neumann and Topel (NT) resume the simultaneous two-dimensional nature (sectoral and geographical) of the pioneering work of Medoff (1983) adding to it a methodological innovation (panel data approach). They try to identify the determinants of persistent, long run unemployment differentials across geographic areas, finding that they emerge because of geographical industrial specialization and the risks associated with it. The maintained hypothesis of the paper is that the unemployment rate is higher in highly specialized regions as workers are mobile within local markets and face an implicit portfolio of employment opportunities which is defined by within market diversification. The higher within-sector uncertainty, alongside high regional industrial specialization, increases equilibrium unemployment. Their empirical findings, using state unemployment data and employment rates by industry between 1948 and 1981, corroborate the importance of demand uncertainty and diversification as determinants of equilibrium unemployment. The SSH receives only moderate support since permanent shifts in sectoral demand composition lead to statistically significant increases in unemployment but the magnitude of their impact is relatively small. This paper is novel in three dimensions: first, it introduces panel data methodologies in the field; second, it stresses the relevance of cross-sectional information; and third, it proposes an interesting new way to proxy for sectoral shifts. Despite plausible reservations about its assumptions, NT91 is an important paper which opened a new viable trail for future research.

Various other studies (Shaw, 1989; Keane, 1991 and 1993; Keane and Prasad, 1996) have also used fixed-effects specifications to investigate the nature of sectoral (inter-industry) wage differentials and their effects on labor reallocation, generally adding to the evidence in support of the SSH (see Table 5 for a brief synopsis of methods and results). These fixedeffect specifications, while practical, substantially restrict the nature of heterogeneity. Moreover, different individuals can in principle be influenced by common factors (see Baltagi, 2008, ch. 12 for a discussion of these issues). Recent work by Bakas et al. (2013) attempts to account for both parameter heterogeneity and cross-sectional dependence in a panel data setting using the common-correlated-effects mean group (CCEMG) estimator Pesaran (2006). They consider the impact of sectoral shocks on unemployment both at the state level and at aggregate level using monthly data over the period 1990-2011 for the 48 
contiguous US states. Labor reallocation in their specification is captured by a purged Lilien's proxy. Their contribution is methodological, as the CCEMG estimator allows them to document a significant and positive impact of labor reallocation on unemployment both at the aggregate and state level. Their findings not only support Lilien's original results, but suggest that previous estimates might under-estimate the effects of labor reallocations on unemployment.

Table 2: Sectorial shifts models and Panel Data

\begin{tabular}{ccccc}
\hline Papers & $\begin{array}{c}\text { Identification } \\
\text { Method }\end{array}$ & Data & $\begin{array}{c}\text { EstimationSectoral Shifts } \\
\text { Procedure Outcomes }\end{array}$ \\
\hline \hline Shaw (1989) & $\begin{array}{c}\text { Dispersion } \\
\text { proxy }\end{array}$ & $\begin{array}{c}\text { US sectoral } \\
\text { data (PSID) }\end{array}$ & $\begin{array}{c}\text { Fixed } \\
\text { Effects }\end{array}$ & $\begin{array}{c}\text { Wages respond to persistent } \\
\text { sectoral shocks (more than to } \\
\text { temporary cyclical shocks). }\end{array}$ \\
\hline $\begin{array}{c}\text { Neumannn and } \\
\text { Topel (1991) }\end{array}$ & $\begin{array}{c}\text { Dispersion } \\
\text { proxy }\end{array}$ & $\begin{array}{c}\text { US sectoral } \\
\text { data (BLS and } \\
\text { census) }\end{array}$ & $\begin{array}{c}\text { Fixed } \\
\text { Effects }\end{array}$ & $\begin{array}{c}\text { Permanent changes in the sectoral composition lead to } \\
\text { transitory increases in unemployment. }\end{array}$ \\
\hline Keane (1991) & Oil Shocks & $\begin{array}{c}\text { US labor } \\
\text { data (NLS) }\end{array}$ & $\begin{array}{c}\text { Fixed } \\
\text { Effects }\end{array}$ & $\begin{array}{c}\text { Oil shocks cause changes } \\
\text { in relative wages and } \\
\text { labor reallocation. }\end{array}$ \\
\hline Keane (1993) & Oil Shocks & $\begin{array}{c}\text { US labor } \\
\text { data (NLS) }\end{array}$ & $\begin{array}{c}\text { Fixed } \\
\text { Effects }\end{array}$ & $\begin{array}{c}\text { Sectoral shocks generate } \\
\text { short run wage differentials } \\
\text { across industries. }\end{array}$ \\
\hline $\begin{array}{c}\text { Keane and } \\
\text { Prasad (1996) }\end{array}$ & $\begin{array}{c}\text { Oil Shocks } \\
\text { Bakas }\end{array}$ & $\begin{array}{c}\text { US labor } \\
\text { data (NLS) }\end{array}$ & $\begin{array}{c}\text { Fixed } \\
\text { Effects }\end{array}$ & $\begin{array}{c}\text { Oil shocks reduce employment in the short run, causing } \\
\text { labor reallocation (support for SSH). }\end{array}$ \\
\hline $\begin{array}{c}\text { Dispersion } \\
\text { Measure }\end{array}$ & $\begin{array}{c}\text { US regional } \\
\text { data (BLS) }\end{array}$ & CCEMG & $\begin{array}{c}\text { Cupport for the SSH. Stress on } \\
\text { importance of cross-sectional } \\
\text { dependence. }\end{array}$ \\
\hline et al. (2012) & $\begin{array}{c}\text { Wage } \\
\text { Composition }\end{array}$ & $\begin{array}{c}\text { US regional } \\
\text { wages (Census) }\end{array}$ & IV & $\begin{array}{c}\text { Shifts in the employment composition have equilibrium } \\
\text { effects on wages. }\end{array}$ \\
\hline
\end{tabular}

(a) Common-Correlated-Effects Mean Group

The effects of changes in the composition of employment and wages is also examined by Beaudry et al. (2012). They ask whether shifts in the mix between high paying sectors and low paying sectors have general equilibrium effects on within sector wages. This question is relevant because general equilibrium effects might be viewed and classified as aggregate shocks, despite deriving from pure reallocation of productive resources. Beaudry et al. argue that a change in industrial composition, through its effect on the bargaining environment, can 


\section{GALLIPOLI, PELLONI Macroeconomic effects of Job Reallocations: A Survey}

affect wages in sectors not directly involved in the compositional change. In such sectors an improved outside option for workers places upward pressure on wages, forcing inefficient firms to exit the market and thereby favoring a reallocation of employment toward more productive firms. The authors look at 10-year and 20-year changes in city-level industryspecific wages using data from the 1970, 1980, 1990 and 2000 US Censuses for 152 cities. They find that changes in city-level industrial composition have significant effects on wages. Such effects are roughly three times larger than what would be predicted by a pure accounting approach. The effect of composition is present over long (20 year) horizons and is present in wages in both tradeable and non-tradeable sectors. By focusing on longer term differences in wage structure, associated to changes in industrial composition, this paper shows how reallocation shocks may induce aggregate effects which become apparent only over long periods.

\section{The Computational Equilibrium Approach}

So far we have shown that much effort has been devoted to assess whether Lilien's original hypothesis is empirically plausible and supported by data. A related line of enquiry has focused on understanding the mechanisms through which sectoral shocks might generate aggregate fluctuations in employment, productivity and output. This line of research is mostly pursued using equilibrium models and numerical analysis. Simulations may allow to disentangle the direct and indirect effects of a specific perturbation and also circumvent data constraints often encountered in econometric work. The standard method of analysis in numerical applications can be summarized as a three-step process: building a structural model which can appropriately address the question of interest; parameterizing the model (the actual estimation/calibration process); and using the fully parameterized model to run experiments and simulate counterfactual scenarios. This final step requires a perturbation of the original equilibrium, resulting in quasi-experimental outcomes.

\subsection{The Attenuating Effects of Aggregation}

At the outset of the RBC literature the supply-side specification of sectoral shocks (i.e., sectoral technology shocks) was the object of research by Long and Plosser (1983). They pose a six-sector G.E. model with intermediate input linkages among sectors and i.i.d. sectoral productivity shocks. At this coarse level of disaggregation their model yields output fluctuations that are both persistent and correlated among sectors. However, attempts to reproduce aggregate volatility at finer levels of disaggregation have not been as successful. The reason is rather straightforward: uncorrelated sector-specific disturbances tend to 
dissipate through aggregation since, by the Law of Large Numbers, positive and negative supply-side variations in different sectors offset each other.

These issues are explored by Horvath (2000) who shows that, within a multi-sector general equilibrium model, aggregate fluctuations with realistic features can be induced by independent sectoral technology shocks. The result is obtained through the introduction of forces which limit the annihilating influence of the Law of Large Numbers. The twist in Horvath's model is the introduction of an input-use matrix with limited interaction, meaning most sectors in the model intensively employ similar intermediate inputs. In this setting sectoral shocks to the intermediate input sectors induce co-movements in the final good sector and provide a sort of micro-foundation for the aggregate productivity shocks described by $\mathrm{RBC}$ researchers. An interesting result is that the process of the Solow residual estimated from simulated data in this highly disaggregated model strongly resembles estimates obtained using aggregate US data. This suggests that multi-factor productivity shocks may partly be an artifact of aggregation, a small step towards a theory of total factor productivity.

\subsection{Sectoral Shocks and Aggregate Productivity Dynamics}

A long standing question in the applied macro literature is how to reconcile sectoral shifts analysis with the observed pattern of pro-cyclical productivity movements and pro-cyclical real wages (see Davis, 1987; Hamilton, 1988; Rogerson, 1987). If aggregate productivity is a weighted average of each sector's productivity, then sectoral shifts may only have a second order effect on TFP dynamics and are unable to match the empirical regularity of pro-cyclical productivity. ${ }^{9}$ A wedge driving the marginal product of different sectors apart is necessary for sectoral reallocation to have a first order effect on aggregate productivity and real wages, and to explain the observation of aggregate increasing returns-to-scale. In what follows we review different approaches to modeling such wedges in sectoral productivity.

Imperfect capital mobility. The work of Ramey and Shapiro (1998) shows that a two-sector model can generate a rich set of business cycle dynamics. They look at shifts in demand

${ }^{9}$ This is true in sectoral models which assume sectoral constant returns to scale (CRS) production functions $Y_{i t}=A_{i t} F_{i}\left(K_{i t}, L_{i t}\right)$ with perfect competition, free mobility of labor $L_{i t}$ and capital stocks $K_{i t}$ that are fixed in the short run. Denoting the labor share in output by $\alpha$ and wage and prices by $w$ and $p$, after a perturbation of the economy from the steady state one can compute a Solow decomposition as:

$$
\widehat{A_{t}}=\widehat{Y_{t}}-\alpha \widehat{L_{t}}=\sum \frac{p_{i} Y_{i}}{Y} \widehat{Y_{l t}}-\alpha \widehat{L_{t}}=\sum \frac{p_{i} Y_{i}}{Y} \widehat{A_{\imath t}}
$$

Here reallocation effects stemming from the movement of labor across sectors have no first-order impact on aggregate productivity. 


\section{GALLIPOLI, PELLONI Macroeconomic effects of Job Reallocations: A Survey}

across sectors due to changes in government spending and assume costly reallocation of capital across sectors. Their model replicates reasonably well the US economy's response to an exogenous military buildup, showing that frictions due to imperfect capital mobility can imply realistic business-cycle dynamics. In related work Rotemberg and Woodford (1992; 1995) and Devereux et al. (1996) argue that models with imperfect competition and increasing returns-to-scale (IRS) can help rationalize the aggregate effects of government spending.

Returns-to-scale and mark-ups. Basu and Fernald (1997b; 2002) ascribe observations of increasing aggregate returns to cyclical movements in the share of production due to durable and non-durable manufacturing. If durables are characterized by higher returns to scale and higher mark-ups than non-durables, a reallocation from the latter to the former results in an increase in aggregate output relative to inputs, as well as in increasing aggregate returns-toscale. Basu and Fernald (1997a) argue that a similar reasoning can be applied to the observation of pro-cyclical aggregate productivity: reallocations from a low returns-to-scale, low mark-up sector to one with high returns and high mark-ups will be partially measured as increases in the Solow residual. It is possible that a reallocation of labor from low to high mark-up sectors would deliver first-order increases in aggregate productivity and that sectoral differences in mark-ups ${ }^{10}$ are the force driving productivity changes. However, differences in mark-ups are relatively small (between 5 and 10\%) and the effects of labor reallocations on aggregate productivity are bound to be correspondingly small.

Capital utilization. A different way to introduce a productivity wedge between sectors is to assume sectoral differences in capital utilization, which result in steady state differences in the marginal productivity of capital. Numerical experiments document that sectoral heterogeneity in capital utilization magnifies the aggregate responses to exogenous sectoral shocks, both in the case of demand side shocks (taste shifts) and in the case of supply side shocks (sectoral productivity). The lack of labor market frictions makes Swanson's model unfit to quantitatively evaluate the impact of sectoral shocks on unemployment. However, this study is a step forward in the theoretical analysis of the SSH as it clearly defines sectoral shifts as any reallocation induced by changes in tastes, government purchases, and sectorspecific technology shocks. In this way he groups under the label of sectoral shocks a wide variety of perturbations which have the common feature of inducing labor reallocation across sectors. Interestingly, pro-cyclical real wages (and productivity) can be obtained from

\footnotetext{
${ }^{10}$ Denoting sectoral markups as $\mu_{i}$ and letting $\mu$ be some measure of the economy-wide average markup, the following decomposition, due to Hall $(1988 ; 1991)$, can be obtained:

$$
\widehat{A_{t}}=\widehat{Y_{t}}-\mu \alpha \widehat{L_{t}}=\sum \frac{p_{i} Y_{i}}{Y} \widehat{A_{l t}}+\alpha \sum\left(\mu_{i}-\mu\right) \widehat{L_{l t}}
$$
}


demand- and supply-side shocks, as long as differences in capital utilization persist among sectors.

\subsection{Labor Market Frictions}

Since Lilien's original contribution labor market frictions have been central to the SSH. The search and matching framework offers a natural counterpart to model sectoral frictions and in what follows we briefly overview some contributions which, in different ways, have adopted it to study the aggregate effects of labor reallocations. Table 3 provides a synopsis of some of the quantitative papers modeling labor frictions explicitly.

An island model with search frictions. Phelan and Trejos (2000) are among the first to parameterize a variant of the frictional labor market in Mortensen and Pissarides (1994). They nest this search model within a two-period adaptation of Lucas and Prescott (1974), with three sectors and three consumption goods produced only through labor. The working question is whether an isolated reallocation shock, such as a permanent change in the composition of demand, can bring about sizable aggregate effects. To isolate the implications of pure technological frictions, Phelan-Trejos-00 solve the dynamic programming problem of a benevolent planner, rather than a decentralized DSGE model. The planner maximizes the expected lifetime utility of a randomly selected agent in an environment with positive costs of job creation. The model is calibrated to match US labor market data and the numerical solution is used to run experiments. In one such experiment a preference shock changes the relative demand for different goods. This is achieved by 'flipping' the preference coefficients of two of the sectors; by construction, this demand shift has no long-run aggregate implications but affects the composition of output and employment. One sector has to decrease in size at the advantage of another, while the third sector, and all aggregate variables, are kept unchanged. The third sector acts as a 'control' sector, allowing one to learn how sectoral shocks propagate to the rest of the economy. The change in the parameters is chosen so that a completed transition brings a reallocation of $3.5 \%$ of the workforce from one sector to the other. What one observes in this experiment is a slow adjustment, as it takes about four years to move halfway from the old to the new steady state, and almost ten years for $80 \%$ of the transition to take place. Employment in the 'control' sector hardly moves. Changes in total employment are small and aggregate changes come from the intensive margin (number of hours) rather than the extensive margin (number of jobs). The latter result is due to the presence of sector-specific convex costs in job creation, which make it very expensive to set up new jobs in the growing sector and tend to preserve employment levels in the shrinking sector. GDP experiences a sizeable drop (1.1\%) along the transition path and this downturn propagates to the third sector, albeit unaffected by the sectoral shock. The combined output of 


\section{GALLIPOLI, PELLONI Macroeconomic effects of Job Reallocations: A Survey}

the expanding and shrinking sector falls because the shrinking sector extracts fewer hours per worker (since the good they produce becomes relatively less attractive) whereas the expanding sector has to divert more resources to the hiring process (to the detriment of production) because of convex costs of job creation. The output response is not small, given the size of the initial impulse and the downturn propagates to the third sector, which was not perturbed, and lasts a long time. The findings are robust to changes in parameters, initial output composition and sector sizes. The dynamics of the adjustment and aggregate downturn induced by the sectoral shock look remarkably similar to those of the US recession during the early 1990s, which was long but not deep and spread unevenly in the economy. Phelan and Trejos (2000) notice that in those years a big military build-down took place and considerable resources were channeled into other sectors.

Measuring mobility costs. The main lesson of Phelan and Trejos's analysis is that reallocation shocks can induce fairly large and persistent aggregate responses when we assume positive costs of moving workers across sectors. But how large are these costs in reality? Lee and Wolpin (2006) attempt to quantify them by looking at the long-term rise in the services sector. They posit a structural model with two sectors (manufacturing and services) and many occupations within each sector: heterogeneous individuals maximize their lifetime utility by choosing whether to work and, if so, in which sector and occupation. Studying the transitional dynamics of employment shares Lee and Wolpin can separately account for the main forces that have led to the long-term rise of the services sector. Estimation results suggest that mobility costs are large. The cost of moving between sectors within the same occupation is estimated to be significantly larger than moving between occupations within the same sector. The cost of switching sectors can be as high as 75 percent of average annual earnings (based on estimates for the 1968-2000 period). In counterfactual experiments Lee and Wolpin find that setting labor mobility costs to zero would result in an almost doubling of aggregate output in equilibrium. This illustrates the huge efficiency loss associated to labor market frictions. Lee and Wolpin also assess the importance of alternative factors for the rise of the services sector, suggesting that demand and technology shocks are responsible for the rise of services' employment rather than demographics and educational changes.

The relevance of technology shocks is also investigated by Andolfatto and MacDonald (2004). They point out that jobless recoveries (i.e. economic expansions which fail to generate jobs in their early stages) might be due to the costly process of labor reallocation induced by technological change. When technological shocks are adopted slowly throughout the economy there can be expansionary periods in which the diversion of labor input towards search and/or human capital accumulation results in no employment gain. Transitional 
periods can therefore be characterized by jobless recoveries. ${ }^{11}$ The fact that jobless recoveries have not been a regular historical occurrence highlights one recurring issue in sectoral shifts analysis: labor reallocation shocks tend to produce aggregate effects only under very specific historical and economic circumstances, a point originally made by Lilien (1982a).

\subsection{The Micro-Macro Approach}

Reassessing the role of the Beveridge curve. Recent work by Mehrotra and Sergeyev (2012) provides a nice bridge between the computational macro literature and the original reduced form approach. Their work is motivated by the observation that the late 2000s recession in the US has featured a slow recovery and a shift in the Beveridge curve, prompting speculation that sector-specific shocks may be behind it. Mehrotra and Sergeyev develop an index of sector-specific shocks, immune to AK's critique, based on sectoral employment in US postwar data and show that this index is correlated with shifts in the Beveridge Curve. Their major insight comes from the careful theoretical analysis of the relationship between different shocks and the Beveridge curve. First, they define the Beveridge curve as the set of unemployment and vacancy combinations traced out by changes in real marginal cost, which reflects the effect of a variety of aggregate disturbances. Under some assumptions they show that aggregate shocks cannot shift this curve. Then, using a sticky-price multi-sector model with labor market frictions and sector-specific shocks, they show that sectoral productivity or demand shocks will, in general, induce outward shifts in the Beveridge curve. The logical conclusion of their analysis is that shifts in the Beveridge curve are a natural candidate to determine whether unemployment dynamics are due to aggregate or sectoral shocks. While the idea of using the Beveridge curve to discriminate between aggregate and sectoral shocks is an old one, Mehrotra and Sergeyev offer a rigorous and novel theoretical setting to frame their analysis. Both their empirical and numerical results indicate that sectoral shifts have been at work at several historical junctures, including during the long recession of the late 2000 s.

Reassessing workers flows: gross vs net. Lilien's original insight has also been revisited in a structural framework by Pilossoph (2012). Her findings are partly consistent with those of Mehrotra and Sergeyev and Phelan and Trejos, suggesting that intersectoral mobility frictions

${ }^{11}$ This is also consistent with a model with no sectoral in which all the loss in labor supply is due to retraining of the labor force to accumulate human capital. A similar conclusion is reached by Tapp (2007) who uses a search model with different sectors to study the effects of changes in international demand for commodities on aggregate employment in Canada between 2002 and 2006. He finds that the transitional costs of relocating labor across sectors were as large as 3\% of GDP and mostly due to the non-transferability of skills across sectors, rather than pure search frictions. 


\section{GALLIPOLI, PELLONI Macroeconomic effects of Job Reallocations: A Survey}

may be an important determinant of aggregate unemployment in the face of sectoral shocks. Pilossoph's model economy brings together the island model of LP74 with frictional labor markets and models of labor mobility that draw from Discrete Choice Theory. Each sector produces a homogeneous intermediate good using only labor. Every period workers draw idiosyncratic sector-specific taste shocks that impact their mobility decisions. If a worker chooses to switch sectors she must pay an additional cost due to forced idleness. In numerical simulations Pilossoph works with two sectors: construction and non-construction.

Table 3: Models with Labor Frictions and Micro-Macro approach

\begin{tabular}{|c|c|c|c|}
\hline Papers & Model & Friction & Sectoral Shifts Outcomes \\
\hline $\begin{array}{l}\text { Phelan and } \\
\text { Trejos (2000) }\end{array}$ & MP94 & $\begin{array}{l}\text { Costs in } \\
\text { job creation }\end{array}$ & $\begin{array}{l}\text { Sectoral shocks may have } \\
\text { large effects on aggregate } \\
\text { output and employment. }\end{array}$ \\
\hline $\begin{array}{l}\text { MacDonald and } \\
\text { Andolfatto (2004) }\end{array}$ & $\mathrm{RBC}$ & $\begin{array}{l}\text { Costs in } \\
\text { labor reallocation }\end{array}$ & $\begin{array}{l}\text { Jobless recoveries may } \\
\text { be caused by sectoral } \\
\text { mobility costs. }\end{array}$ \\
\hline $\begin{array}{c}\text { Lee and } \\
\text { Wolpin (2006) }\end{array}$ & $\begin{array}{l}\text { Structural Model } \\
\text { with two sectors }\end{array}$ & $\begin{array}{l}\text { Switching } \\
\text { costs }\end{array}$ & $\begin{array}{l}\text { Sectoral mobility } \\
\text { costs are large. }\end{array}$ \\
\hline $\begin{array}{c}\text { Mehrotra and } \\
\text { Sergeyev (2012) }\end{array}$ & $\begin{array}{l}\text { Multisector New } \\
\text { Keynesian model }\end{array}$ & $\begin{array}{l}\text { Reallocation } \\
\text { costs }\end{array}$ & $\begin{array}{c}\text { Sector-specific shocks } \\
\text { shift the Beveridge curve } \\
\text { and affect unemployment }\end{array}$ \\
\hline Pilossoph (2012) & LP74 and MP94 & $\begin{array}{l}\text { Frictional } \\
\text { intersectoral mobility }\end{array}$ & $\begin{array}{l}\text { Critique of Lilien: Dispersion } \\
\text { shocks do not necessarily } \\
\text { increase aggregate } \\
\text { unemployment. }\end{array}$ \\
\hline
\end{tabular}

The model is estimated using CPS data and, once fully parameterized, it is used to identify and quantify the shocks that hit the construction and non-construction sectors between 19772012. Crucially, in her work Pilossoph challenges Lilien's original tenet that an increase in the dispersion of sectoral shocks must lead to increases in aggregate unemployment. Lilien's underlying assumption is that an increase in the dispersion of sectoral shocks leads to an increase in net reallocation of labor which in turn increases aggregate unemployment through higher unemployment duration for movers. Pilossoph argues that whether or not Lilien's insight is correct depends on whether gross worker flows exceed net worker flows. When they do, shocks that require net reallocation may have little impact on the total number of movers 
because the total number of people transiting across sectors does not change much. Thus, it is not clear that Lilien's predictions hold in this case. In a direct test of Lilien's hypothesis she shows that, when gross reallocation is not equal to net reallocation, with the second being small, aggregate unemployment does not necessarily increase when the dispersion of sectoral shocks increases. This result provides an interesting explanation for the findings of Loungani and Rogerson (1989) and others, discussed in Section 5, which suggest that total gross reallocation is relatively acyclic while the number of movers within sectors displays a prominent cyclical pattern. This is something that Pilossoph's model can clearly explain by resorting to the fact that the flow of labor into cyclically more sensitive sectors increases during booms and declines during recessions; if these flows cancel out in the aggregate, the total gross reallocation over the cycle is relatively acyclic.

\section{Conclusions}

In this article we have critically surveyed several generations of empirical studies on the macroeconomic effects of job reallocations, from 1982 to date. The first attempts at studying the effects of sectoral reallocation of labor are based on the estimation of standard reduced form unemployment equation augmented by an index approximating the dispersion of sectoral employment changes. It did not take much time for the literature to point out that this approach is plagued by a severe problem of observational equivalence, deriving from the fact that the employment dispersion index responds to both aggregate impulses and sectoral reshuffling of workers.

A second generation of empirical studies try to solve this identification problem by simply purging sectoral dispersion proxies of aggregate influences. The choice of purging method, however, has proven to be controversial because different purging procedures result in contrasting findings. In general, the empirical results of first and second generation models are not quite favorable to the sectoral shifts hypothesis.

The third generation of tests, still based on dispersion indexes, appeared in the early 1990s. The key feature of this approach is the use of stock market and accounting data to proxy the intensity of sectoral reallocation of workers. Still, these models have been subjected to similarly harsh criticism because they cannot discriminate between aggregate and idiosyncratic shocks. Moreover stock market values do not necessarily capture the nature and extent of labor reallocation.

The early debate of the SSH is also framed in terms of the unemployment-vacancy relationship, and the relationship between proxies of labor reallocation and the Beveridge curve have been the object of much empirical interest until theoretical work by Hosios has shown that, at least in its early shape, this strategy was a dead end. 


\section{GALLIPOLI, PELLONI Macroeconomic effects of Job Reallocations: A Survey}

Structural Vector Auto-Regressions (SVAR) are the analytical tool introduced by the fourth generation studies. SVARs have the benefit of dispensing with generated dispersion indexes. This strategy brings a gain in terms of correct inference, by getting rid of generated regressors, and avoids the thorny issue of purging. Nevertheless, it is exposed to the standard criticisms to SVAR modeling. Perhaps more importantly, the VAR approach tends to miss the non-directional nature of sectoral shocks. As we discuss in our overview, one of the fundamental features of sectoral shifts is that shocks which reallocate labor result in higher unemployment regardless of whether the reallocation is due to sectors growing or shrinking. Put simply, the sectoral shifts hypothesis in its purest form does not classify individual shocks as positive or negative nor assigns a directional effect to shocks. What matters is that a new need arises to reallocate labor across sectors. Therefore, within the SVAR literature, extensions based on multivariate GARCH-M models, which can capture the effects of volatility in labor reallocation, appear the most promising.

A fundamental step towards modeling the effects of pure reallocation, irrespective of whether shocks are good or bad, is taken by the next generation of studies. These are based on job-creation and job-destruction models which provide a suitable conceptual framework to analyze rich sources of micro-data. More importantly, the development of these concepts has allowed researchers to formulate and test specific restrictions based on the amount of job reshuffling. In terms of data sources, micro-data have proven to be a valuable source of information about labor reallocation, and have become increasingly popular also outside the JC and JD literature. The usefulness of micro-data has also been enhanced by recent advances in panel data econometrics.

While most studies using micro-data find evidence of significant inter- and intra-sectoral job reallocation, disagreement persists over the relative importance of sectoral shocks in driving aggregate unemployment fluctuations. Such disagreement partly stems from the lack of an accepted, rigorous conceptual framework to differentiate aggregate and sectoral shocks. The lack of a clear theoretical benchmark makes measurement harder. The computational equilibrium approach to the analysis of sectoral shocks is an attempt to overcome the underlying uncertainty about the nature of reallocation shocks by making explicit assumptions which are directly reflected in simulation results. Reasonably calibrated models of the aggregate economy are effectively used to account for different sources of aggregate unemployment swings. This line of research has the advantage of being capable to easily discriminate between alternative theoretical hypothesis regarding the mechanisms through which sectoral shocks operate.

At the end of this long excursion it is possible to state that we are still far from a fully satisfactory empirical practice to assess the macroeconomic effects of job reallocations. 
However, since the early days of Lilien's seminal work a lot of ground has been conquered. While the large body of evidence we have reviewed fails to provide narrow bounds on the quantitative role of sectoral shifts for employment fluctuations, our survey suggests that it is reasonable to conclude that sectoral reallocation of resources is likely responsible for no less that $1 / 4$ and no more that $2 / 3$ of the variance of aggregate employment in postwar data. While this range may seem wide, perhaps it is also an indication of the fact that the role of labor reallocation may change over time. For example, at particular historical junctures like the 1970 s or the late 2000 s, labor reallocation played a much larger role than at other points in time.

\section{References}

Aaronson, Daniel, Ellen R. Rissman and Daniel G Sullivan (2004), Can Sectoral Reallocation Explain the Jobless Recovery?, Economic Perspectives, Federal Reserve Bank of Chicago, 28, 36-49.

Abraham, Katharine G., and Lawrence F. Katz (1984), Cyclical Unemployment: Sectoral Shifts or Aggregate Disturbances?, , National Bureau of Economic Research, w1410.

Abraham, Katharine G., and Lawrence F. Katz (1986): Cyclical Unemployment: Sectoral Shifts or Aggregate Disturbances?, Journal of Political Economy, 94(3), 507-522.

Acconcia, Antonio and Saverio Simonelli (2008), Interpreting Aggregate Fluctuations Looking at Sectors, Journal of Economic Dynamics and Control, 32, 3009-3031.

Andolfatto, David and Glenn MacDonald (2004), Modeling a Jobless Recovery. Meeting Papers, 298, Society for Economic Dynamics.

Bakas, Dimitrios, Theodore Panagiotidis and Gianluigi Pelloni (2013), Panel Reallocation: Panel Evidence from U.S. States, The Rimini Centre for Economic Analysis WP 13-26.

Baldwin, John, Timothy Dunne and John Haltiwanger (1998), A Comparison Of Job Creation And Job Destruction In Canada And The United States, The Review of Economics and Statistics, 80(3), 347-356.

Baltagi, Badi (2008), Econometric Analysis of Panel Data. Wiley, 4th edn.

Barnichon, Regis (2010), Building a Composite Help-Wanted Index, Economics Letters, 109(3), 175-178.

Basu, Susanto and John G. Fernald (1997a), Aggregate Productivity and Aggregate Technology, International Finance Discussion Papers, 593, Board of Governors of the Federal Reserve System.

Basu, Susanto and John G. Fernald (1997b), Returns to Scale in U.S. Production: Estimates and Implications, Journal of Political Economy, 105(2), 249-283. 


\section{GALLIPOLI, PELLONI Macroeconomic effects of Job Reallocations: A Survey}

Basu, Susanto, and John G. Fernald (2002), Aggregate Productivity and Aggregate Technology, European Economic Review, 46(6), 963-991.

Beaudry, Paul, David A. Green and Benjamin Sand (2012), Does Industrial Composition Matter for Wages? A Test of Search and Bargaining Theory, Econometrica, 80(3), 10631104.

Black, Fischer. Exploring General Equilibrium. MIT Press, 1995.

Blanchard, Olivier J. and Philip A. Diamond (1989), The Beveridge Curve, Brookings Papers on Economic Activity, 1, 1-60.

Blanchard, Olivier J, and Quah, Danny (1989), The Dynamic Effects of Aggregate Demand and Supply Disturbances, American Economic Review, 79(4), 655-73.

Bloom, Nicholas (2009), The Impact of Uncertainty Shocks, Econometrica, 77(3), 623-685.

Brainard, S. Lael. (1992), Sectoral Shifts and Unemployment in Interwar Britain, National Bureau of Economic Research, w3980.

Brainard, S. Lael, and David M. Cutler (1993), Sectoral Shifts and Cyclical Unemployment Reconsidered, The Quarterly Journal of Economics, 108, 219-244.

Byun, Yanggyu, and Hae-Shin Hwang (2006), Measurements of Sectoral Shifts: Dispersion and Skewness, Working Paper, Department of Economics, Texas A\&M University.

Caballero, Ricardo J., Eduardo MRA Engel, and John Haltiwanger (1997), Aggregate Employment Dynamics: Building from Microeconomic Evidence, American Economic Review, 87(1), 115-37.

Campbell, Jeffrey R., and Kenneth N. Kuttner (1996), Macroeconomic Effects of Employment Reallocation, Carnegie-Rochester Conference Series on Public Policy, 44, 87-116.

Caporale, Tony, K. Doroodian, and M. R. M. Abeyratne (1996), Cyclical Unemployment: Sectoral Shifts or Aggregate Disturbances? A Vector Autoregression Approach, Applied Economics Letters, 3(2), 127-30.

Kannan, Prakash, Prakash Loungani, and Bharat Trehan (2011), New Evidence on Cyclical and Structural Sources of Unemployment, Discussion paper, International Monetary Fund, IMF Working Papers 11/106.

Davis, Steven J., (1987), Allocative Disturbances and Specific Capital in Real Business Cycle Theories, American Economic Review, 77, 326-332.

Davis, Steven J., and John Haltiwanger (1990), Gross Job Creation and Destruction: Microeconomic Evidence and Macroeconomic Implications, NBER Macroeconomics Annual 1990, Volume 5. MIT Press, 123-186.

Davis, Steven J., and John Haltiwanger (1992), Gross Job Creation, Gross Job Destruction, and Employment Reallocation, The Quarterly Journal of Economics, 107(3), 819-63. 
Davis, Steven J., and John Haltiwanger (1999), On the Driving Forces behind Cyclical Movements in Employment and Job Reallocation, American Economic Review, 89(5), 1234-1258.

Davis, Steven J., and John Haltiwanger (2001), Sectoral Job Creation and Destruction Responses to Oil Price Changes, Journal of Monetary Economics, 48(3), 465-512.

Davis, Steven J., John Haltiwanger, Ron Jarmin, and Javier Miranda (2006), Volatility and Dispersion in Business Growth Rates: Publicly Traded Versus Privately Held Firms, Paper prepared for the 2006 NBER Macroeconomics Annual.

Davis, Steven J., R. Jason Faberman, John Haltiwanger, Ron Jarmin, and Javier Miranda (2008), Business Volatility, Job Destruction, and Unemployment, National Bureau of Economic Research, w14300.

Davis, Steven J., John Haltiwanger, and Scott Schuh (1996), Small Business and Job Creation: Dissecting the Myth and Reassessing the Facts, Small Business Economics, 8(4),297-315.

Devereux, Michael B., Allen C. Head, and Beverly J. Lapham (1996), Monopolistic Competition, Increasing Returns, and the Effects of Government Spending, Journal of Money, Credit and Banking, 28(2), 233-254.

Diamond, Peter (2013), Cyclical Unemployment, Structural Unemployment. National Bureau of Economic Research, w18761.

Faberman, R. Jason (2006), Job Flows and the Recent Business Cycle: Not all Recoveries are Created Equal. Working Paper Series, 39, U.S. Bureau of Labor Statistics.

Faust, Jon, and Eric M. Leeper (1997), When Do Long-Run Identifying Restrictions Give Reliable Results?, Journal of Business \& Economic Statistics, 15(3), 345-53.

Foerster, Andrew T., Pierre-Daniel G. Sarte, and Mark W. Watson. (2008) Sectoral vs. Aggregate Shocks: A Structural Factor Analysis of Industrial Production, National Bureau of Economic Research, w14389.

Foote, Christopher L. (1998), Trend Employment Growth And The Bunching Of Job Creation And Destruction, The Quarterly Journal of Economics, 113(3), 809-834.

Fortin, Mario, and Abdelkrim Araar (1997), Sectoral Shifts, Stock Market Dispersion and Unemployment in Canada, Applied Economics, 29(6), 829-39.

Gourinchas, Pierre-Olivier (1998), Exchange Rates and Jobs: What Do We Learn from Job Flows?, National Bureau of Economic Research, w6864.

Groshen, Erica L., and Simon Potter (2003), Has Structural Change Contributed to a Jobless Recovery, Current Issues in Economics and Finance, 9(8), 1-7.

Hall, Robert E. (1988), The Relation Between Price and Marginal Cost in US Industry, Journal of Political Economy, 96(5), 921-947. 


\section{GALLIPOLI, PELLONI Macroeconomic effects of Job Reallocations: A Survey}

Hall, Robert E. (1991), Invariance properties of Solow's productivity residual, National Bureau of Economic Research, w3034.

Haltiwanger, John, Adriana Kugler, Maurice Kugler, Alejandro Micco and Carmen Pages (2004), Effects of Tariffs and Real Exchange Rates on Job Reallocation: Evidence from Latin America, Journal of Policy Reform, 7(4), 191-208.

Hamilton, James D. (1988): A Neoclassical Model of Unemployment and the Business Cycle, Journal of Political Economy, 96(3), 593-617.

Harvey, Andrew, Esther Ruiz, and Neil Shephard (1994), Multivariate Stochastic Variance Models, The Review of Economic Studies, 61(2), 247-264.

Horvath, Michael (2000), Sectoral Shocks and Aggregate Fluctuations, Journal of Monetary Economics, 45(1), 69-106.

Hosios, Arthur J. (1994), Unemployment and Vacancies with Sectoral Shifts, The American Economic Review, 84(1), 124-144.

Johnson, George E., and P. Richard G. Layard (1986), The Natural Rate of Unemployment : Explanation and Policy, in Handbook of Labor Economics, ed. by O. Ashenfelter, and R. Layard, vol. 2, 921-999. Elsevier, North-Holland.

Keane, Michael P. (1991), Sectoral Shift Theories of Unemployment: Evidence from Panel Data, Institute for Empirical Macroeconomics, Federal Reserve Bank of Minnaepolis, Research Department, Discussion Paper 28.

Keane, Michael P. (1993), Individual Heterogeneity and Interindustry Wage Differentials, Journal of Human Resources, 28(1), 134-161.

Keane, Michael P., and Eswar S. Prasad (1996), The Employment and Wage EFFects of Oil Price Changes: A Sectoral Analysis, Review of Economics and Statistics, 78(3), 389-400.

King, Robert, and Mark Watson (1992), Testing Long Run Neutrality, National Bureau of Economic Research, w4156.

King, Robert, and Mark Watson (1997), Testing Long-Run Neutrality, FRB Richmond Economic Quarterly 83(3), 69-101.

Klein, Michael W., Scott Schuh, and Robert K. Triest. (2002), Job Creation, Job Destruction, and International Competition: a Literature Review, Working Paper No. 02-7, Federal Reserve Bank of Boston.

Klein, Michael W., Scott Schuh, and Robert K. Triest. (2003), Job Creation, Job Destruction, and the Real Exchange Rate, Journal of International Economics, 59(2), 239-265.

Lancaster, Tony (1979), Econometric Methods for the Duration of Unemployment, Econometrica, 47(4), 939-956.

Lee, Donghoon and Kenneth I. Wolpin (2006), Intersectoral Labor Mobility and the Growth of the Service Sector, Econometrica, 74(1),1-46. 
Lilien, David M. (1982a), A sectoral Model of Business Cycle, MRG WP no. 8231, University of Southern California, 1982.

Lilien, David M. (1982b), Sectoral Shifts and Cyclical Unemployment, The Journal of Political Economy, 90, 777-793.

Lippi, Marco and Lucrezia Reichlin (1993), The Dynamic Effects of Aggregate Demand and Supply Disturbances: Comment, American Economic Review, 83(3), 644-52.

Long, John B., and Charles I. Plosser (1983), Real Business Cycles, The Journal of Political Economy, 91,1345-1370.

Long, John B., and Charles I. Plosser (1987), Sectoral vs. Aggregate Shocks in the Business Cycle, American Economic Review, 77, 333-336.

Loungani, Prakash (1986), Oil Price Shocks and the Dispersion Hypothesis, The Review of Economics and Statistics, 68(3), 536-39.

Loungani, Prakash and Richard Rogerson (1989), Cyclical Fluctuations and Sectoral Reallocation: Evidence from the PSID, Journal of Monetary Economics, 23(2), 259-273.

Loungani, Prakash, Richard Rogerson and Y-H Sonn (1989), Unemployment and Sectoral Shifts: Evidence from the PSID, Papers, 89-1, Florida College of Business Administration

Loungani, Prakash, Mark Rush, and William Tave (1991), Stock Market Dispersion and Business Cycles, Economic Persepctives, 15 (4), 2-8.

Loungani, Prakash, and Bharat Trehan (1997), Explaining Unemployment: Sectoral vs. Aggregate Shocks, Economic Review, 3-15.

Lucas, Robert E., and Edward C. Prescott (1974), Equilibrium Search and Unemployment, Journal of Economic Theory, 7(2), 188-209.

Medoff, James L. (1983), U.S. Labor Markets: Imbalance, Wage Growth, and Productivity Growth in the 1970's, Brookings Papers on Economic Activity, 1983.

Mehrotra, Neil R., and Dmitriy Sergeyev (2012), Sectoral Shocks, the Beveridge Curve and Monetary Policy. Tech. rep., Columbia University.

Mills, Terence C., Gianluigi Pelloni, and Athina Zervoyianni (1995), Fluctuations in the US: Further Tests of the Sectoral Shifts Hypothesis," The Review of Economics and Statistics, 77, 294-304.

Mills, Terence C., Gianluigi Pelloni, and Athina Zervoyianni (1996), Unemployment and Sectoral Shifts: Further Tests of the Lilien Hypothesis for the UK," Economic Letters, 52, 11-58.

Mills, Terence C., Gianluigi Pelloni, and Athina Zervoyianni (1997), Unemployment Fluctuations in the UK: 1958-1992," Applied Economics Letters, 4(4).

Mortensen, Dale T., and Christopher A. Pissarides (1994), Job Creation and Job Destruction in the Theory of Unemployment, Review of Economic Studies, 61(3), 397-415. 


\section{GALLIPOLI, PELLONI Macroeconomic effects of Job Reallocations: A Survey}

Mortensen, Dale T., and Christopher A. Pissarides (1999), Job Reallocation, Employment Fluctuations and Unemployment," in Handbook of Macroeconomics, ed. by J. B. Taylor, and M. Woodford, vol. 1 of Handbook of Macroeconomics, chap. 18, 1171-1228.

Murphy, Kevin M., and Robert H. Topel. (1989), The Evolution of Unemployment in the United States: 1968-1985, NBER Reprints, 1209.

Neelin, Janet. (1987), Sectoral Shifts and Canadian Unemployment, Review of Economics and Statistics, 59, 718-723.

Neumann, George R. and Robert H. (1991), Employment Risk, Diversification, and Unemployment, The Quarterly Journal of Economics, 106(4),1341-1365.

Palley, Thomas I. (1992), Sectoral Shifts and Cyclical Unemployment: A Reconsideration, Economic Inquiry, 30(1), 117-133.

Panagiotidis, Theodore and Gianluigi Pelloni (2013) Employment Reallocation and Unemployment Revisited: A Quantile Regression Approach, Rimini Centre for Economic Analysis, Working Papers wp13-01. Also available. as Working Papers wp881, Dipartimento Scienze Economiche, Universita' di Bologna, 2013.

Panagiotidis, Theodore, Gianluigi Pelloni and Wolfgang Polasek (2003), Aggregate Effects of Reallocation Shocks: A Generalized Impulse Response Function Analysis for Four European Countries, Journal of Economic Integration.

Pelloni, Gianluigi and Wolfgang Polasek (1999), Intersectoral Labour Reallocation and Employment Volatility: A Bayesian Analysis Using a VAR-GARCH-M Model, Discussion Paper, 99, Department of Economics, University of York, 1999.

Pelloni, Gianluigi and Wolfgang Polasek (2003), Macroeconomic Effects of Sectoral Shocks in Germany, the U.K., U.S.: a VAR-GARCH-M Approach, Computational Economics, 21,65-85.

Pesaran, M. Hashem (2006), Estimation and Inference in Large Heterogeneous Panels with a Multifactor Error Structure, Econometrica, 74, 967-1012.

Pesaran, M. Hashem, and Robert A. Evans (1984), Inflation, Capital gains and U.K. Personal Savings: 1953-1981, The Economic Journal, 94(374), 237-257.

Phelan, Christopher, and Alberto Trejos (2000), The Aggregate Effects of Sectoral Reallocations, Journal of Monetary Economics, 45(2), 249-268.

Edmund S. Phelps (1970), Microeconomic Foundations of Employment and Ination Theory, New York: Norton.

Pilossoph, Laura (2012), A Multisector Equilibrium Search Model of Labor Reallocation, $\mathrm{PhD}$ thesis, The University of Chicago.

Pissarides, Christopher A (1985), Short-run Equilibrium Dynamics of Unemployment Vacancies, and Real Wages, American Economic Review, 75(4), 676-90. 
Ramey, Valerie A. and Matthew D. Shapiro (1998), Costly Capital Reallocation and the Effects of Government Spending. Carnegie-Rochester Conference Series on Public Policy, 48,145-194.

Ricardo, David (1817): On the Principles of Political Economy and Taxation. John Murray, $3 r d$ edn.

Rissman, Ellen R. (2003), Can Sectoral Reallocation Explain the Jobless Recovery?, Essays on Issues, 197, Federal Reserve Bank of Chicago.

Rogerson, Richard. (1987): An Equilibrium Model of Sectoral Reallocation," Journal of Political Economy, 95(4), 824-834.

Romer, Christina D., and David H. Romer (2004), A New Measure of Monetary Shocks: Derivation and Implications, American Economic Review, 94(4), 1055-1084.

Rotemberg, Julio J., and Michael Woodford (1992), Oligopolistic Pricing and the Effects of Aggregate Demand on Economic Activity, Journal of Political Economy, 100, 1152-1207.

Rotemberg, Julio J., and Michael Woodford (1995), Dynamic General Equilibrium Models with Imperfectly Competetitive Product Markets, in Frontiers of Business Cycle Research, ed. By T. F. Cooley, chap. 9. Princeton University Press, Princeton.

Samson, Lucie (1990), Sectoral Shifts and Aggregate Unemployment: Additional Empirical Evidence, Applied Economics, 22, 331-346.

Schuh, Scott, and Robert K. Triest (1988), Job Reallocation And The Business Cycle: New Facts for an Old Debate, Discussion Paper, Federal Reserve Bank Of Boston.

Shaw, Kathryn L. (1989), Wage Variability in the 1970s: Sectoral Shifts or Cyclical Sensitivity, The Review of Economics and Statistics , 71(1), 26-36.

Sheffrin, Steven M. (1997), The Dispersion Hypothesis in Macroeconomics, The Review of Economics and Statistics, 66(3), 482-485.

Shiller, Robert (2005), Irrational Exuberance, Princeton University Press, 2nd edn.

Shiller, Robert (2008): The Subprime Solution: How Today's Global Financial Crisis Happened, and What to Do About It. Princeton University Press.

Shin, Kwanho (1997), Inter- and Intrasectoral Shocks: Effects on the Unemployment Rate, Journal of Labor Economics, 15(2), 376-401.

Starr-McCluer, Martha (1993), Cyclical Fluctuations and Sectoral Reallocation : A Reexamination, Journal of Monetary Economics, 31(3), 417-425.

Storer, Paul (1996), Separating the Effects of Aggregate and Sectoral Shocks with Estimates from the Markov-switching Search Model, Journal of Economic Dynamics and Control, 20 (1), 93-121.

Swanson, Eric (1999), Models of Sectoral Reallocation, Finance and Economics Discussion Series 1999-03, Board of Governors of the Federal Reserve System. 


\section{GALLIPOLI, PELLONI Macroeconomic effects of Job Reallocations: A Survey}

Tapp, Stephen (2007), The Dynamics of Sectoral Labour Adjustment, Working Papers, 1141, Queen's University, Department of Economics.

Thomas, Jonathan M. (1996), An Empirical Model of Sectoral Movements by Unemployed Workers, Journal of Labor Economics, 14(1), 126-153.

Weiss, Laurence (1986), Asymmetric Adjustment Costs and Sectoral Shifts, In W. P. Heller,

R.M. Starr and D.A. Starret, editors, Equilibrium Analysis: Essays in Honor of Kenneth J. Arrow. CUP, Cambridge.

\section{Legend for Abbreviations}

\section{Technical Jargon}

- $\quad$ ACROSS = Dispersion Index Across Industries; Inter-sectoral reallocation

- $\mathrm{BED}=$ Business Employment Dynamics

- $\mathrm{BLS}=$ Bureau of Labor Statistics

- $\mathrm{CAPM}=$ Capital Asset Pricing Model

- $\mathrm{CPS}=$ Current Population Survey

- $\mathrm{CRS}=$ Constant Return to Scale

- $\mathrm{CSV}=$ Cross-Section Volatility

- $\quad \mathrm{DSGE}=$ Dynamic Standard General Equilibrium

- $\mathrm{EXC}=$ Excess Job Reallocation

- $\mathrm{GE}=$ General Equilibrium

- GIRF = Generalized Impulse Response Function

- $\mathrm{HWI}=$ Help-Wanted-Advertising Index

- $\quad$ IRF $=$ Impulse Response Function

- $\quad$ IRS = Increasing Aggregate Return to Scale

- $\mathrm{JC}=$ Job Creation

- $\mathrm{JD}=$ Job Destruction

- $\mathrm{LBD}=$ Longitudinal Business Database

- $\quad \mathrm{LRD}=$ Longitudinal Research Database

- $\mathrm{RH}=$ Reallocation Hypothesis

- $\mathrm{MSSV}=$ Markov Switching Stochastic Volatility

- $\mathrm{NAICS}=$ North American Industry Classification System

- $\mathrm{NET}=$ Employment change

- $\quad \mathrm{NRU}=$ Natural Rate of Unemployment

- $\quad$ OLS = Ordinary Least Squares

- $\quad$ PPLR = Past-Pattern-of-Labor-Reallocation

- $\quad$ PSID = Panel Study of Income Dynamics 
- $\quad \mathrm{RBC}=$ Real Business Cycle

- $\mathrm{SBCE}=$ Stage-of-Business-Cycle Effect

- $\mathrm{SIC}=$ Standard Industrial Classification

- $\mathrm{SSH}=$ Sectoral Shifts Hypothesis

- STAR $=$ Smooth Transition Autoregressive Model

- $\mathrm{SUM}=$ Net job creation, gross job reallocation

- $\mathrm{SVAR}=$ Structural VAR

- SWARCH = Switching ARCH

- $\mathrm{VAR}=$ Vector Auto-Regression

- VAR-GARCH-M = Multivariate GARCH in Mean

- WITHIN = Dispersion Index Within Industries; Intra-Sectoral Reallocation

\section{Authors Abbreviations}

- $\mathrm{AK}=$ Abraham, K. G., and L. F. Katz $(1984 ; 1986)$

- $\quad$ BC93 = Brainard, S. and D. Cutler (1993)

- BPP13 = Bakas, D., T. Panagiotidis, and G. Pelloni (2013)

- BH06 = Byun, Y., and H.-S. Hwang (2006)

- $\quad$ CKLT11 = Chen, J., P. Kannan, P. Loungani, and B. Trehan (2011)

- $\quad$ K91 = Keane, M. P. (1991)

- KP96 = Keane, M. P., and E. S. Prasad (1996)

- $\quad$ LP74 = Lucas, R. E., and E. C. Prescott (1974)

- MP94 = Mortensen, D. T., and C. Pissarides (1994)

- $\quad M S 12=$ Mehrotra, N. R., and D. Sergeyev (2012)

- $\mathrm{MPZ}=$ Mills, T., G. Pelloni, and A. Zervoyanni $(1995 ; 1996 ; 1997)$

- $\quad$ NT91 = Neumann, G. R., and R. H. Topel (1991) 